\title{
Using Functional Electrical Stimulation Mediated by Iterative Learning Control and Robotics to Improve Arm Movement for People With Multiple Sclerosis
}

\author{
Patrica Sampson, Chris Freeman, Susan Coote, Sara Demain, Peter Feys, Katie Meadmore, and \\ Ann-Marie Hughes
}

\begin{abstract}
Few interventions address multiple sclerosis (MS) arm dysfunction but robotics and functional electrical stimulation (FES) appear promising. This paper investigates the feasibility of combining FES with passive robotic support during virtual reality (VR) training tasks to improve upper limb function in people with multiple sclerosis (pwMS). The system assists patients in following a specified trajectory path, employing an advanced model-based paradigm termed iterative learning control (ILC) to adjust the FES to improve accuracy and maximise voluntary effort. Reaching tasks were repeated six times with ILC learning the optimum control action from previous attempts. A convenience sample of five pwMS was recruited from local MS societies, and the intervention comprised 18 one-hour training sessions over 10 weeks. The accuracy of tracking performance without FES and the amount of FES delivered during training were analyzed using regression analysis. Clinical functioning of the arm was documented before and after treatment with standard tests. Statistically significant results following training included: improved accuracy of tracking performance both when assisted and unassisted by FES; reduction in maximum amount of FES needed to assist tracking; and less impairment in the proximal arm that was trained. The system was well tolerated by all participants with no increase in muscle fatigue reported. This study confirms the feasibility of FES combined with passive robot assistance as a potentially effective intervention to improve arm movement and control in pwMS and provides the basis for a follow-up study.
\end{abstract}

Index Terms-Functional electrical stimulation (FES), iterative learning control (ILC), Multiple Sclerosis (MS), rehabilitation, robot-therapy, upper limb, virtual reality (VR).

Manuscript received May 09, 2014; revised November 05, 2014 and January 29, 2015; accepted March 13, 2015. Date of publication March 24, 2015; date of current version nulldate. This work was supported by the Multiple Sclerosis Society in the U.K. under Grant 973/12.

P. Sampson, S. Demain, and A.-M. Hughes are with the Rehabilitation and Health Technologies Research Group, Faculty of Health Sciences, University of Southampton, U.K. (e-mail: P.Sampson@soton.ac.uk; S.H.Demain@soton. ac.uk; A.Hughes@soton.ac.uk).

C. Freeman and K. Meadmore are with Faculty of Physical Sciences and Engineering; University of Southampton, Southampton SO17 1BJ, U.K. (e-mail: cf@ecs.soton.ac.uk; klm301@soton.ac.uk).

S. Coote is with the Clinical Therapies Department, University of Limerick, Castletroy, Co., Limerick, Ireland (e-mail: Susan.Coote@ul.ie).

P. Feys is with REVAL/BIOMED Research Institute, Hasselt University, 3900 Diepenbeek, Belgium (e-mail: peter.feys@uhasselt.be).

Color versions of one or more of the figures in this paper are available online at http://ieeexplore.ieee.org.

Digital Object Identifier 10.1109/TNSRE.2015.2413906

\section{INTRODUCTION}

\section{$\mathbf{M}$} ULTIPLE SCLEROSIS (MS) is a chronic, degenerative, autoimmune disorder, which affects the central nervous system leading to a wide range of symptoms including upper limb weakness. Despite advances in pharmaceutical options to reduce the number and severity of relapses, rehabilitation continues to play an essential role in reducing motor disability in people with MS (pwMS) [1]. However, studies relating to rehabilitation of the upper limb in MS remain limited [2] despite the high percentage of pwMS who have upper limb symptoms, classified within the impairments and activity domains of the International Classification of Functioning Disability and Health (ICF). Using the nine hole peg test (9HPT) $76 \%$ of 219 pwMS were identified to have reduced manual dexterity [3] and $50 \%(n=219)$ and $67 \%(n=166)$ of pwMS experience limitations in activities of daily living (ADL) and social activities, respectively, [3], [4]. Arm and hand use is important to enable independence in everyday life, however effective treatment strategies for the impaired upper limb are not currently available. In degenerative neurological conditions such as MS the aim of rehabilitation is on improving or maintaining a person's current function and independence for as long as possible. PwMS most often only show arm dysfunction at later stages of the disease, when the MS disease course has become progressive instead of relapsing-remitting. However, progression can be slow, so benefits obtained from focused interventions can lead to functional improvements lasting from months to years. The purpose of the intervention is not muscle strengthening per se, but improving motor coordination of multiple limb segments, with focus on the quality of the executed movement. In that sense, the approach is impairment based as well as different to, for example, constrained induced movement therapy, which allows compensatory movements during functional activities. FES is however applicable in severely disabled upper limbs, and is thought to provide a neural sound basis for further functional rehabilitation. New strategies to achieve this rehabilitation aim need to be developed and evaluated.

The essential component of sensory-motor training in both healthy and impaired people is intensive practice in an environment that provides varied challenging tasks, success and sensory-motor feedback of performance that enhance motivation and attention [5]. Functional electrical stimulation (FES) and 


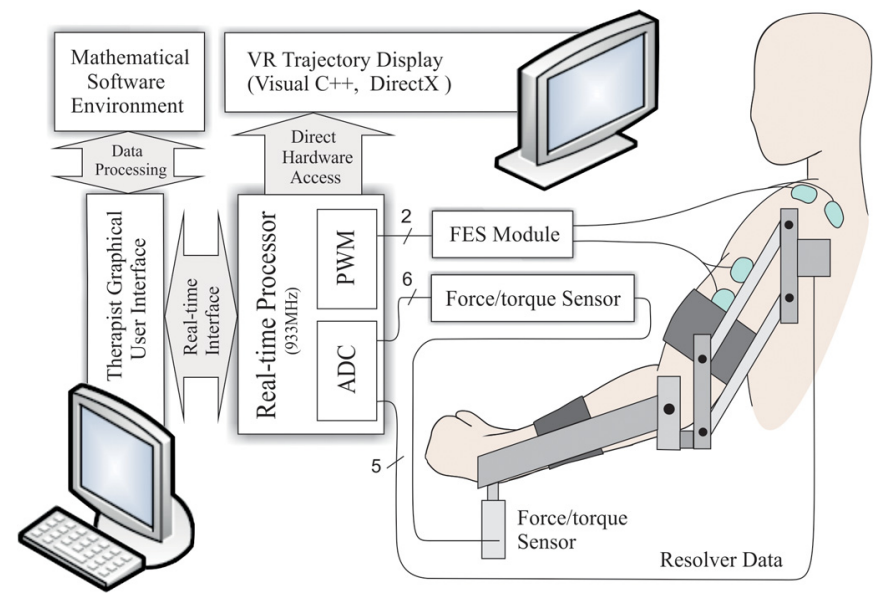

Fig. 1. Signal flow diagram showing system components: passive robot; realtime processor; FES hardware; therapist and participant displays.

passive or active robotic systems are ideally placed to deliver these type of interventions.

FES has been shown to be effective in augmenting strength in healthy people [6], stroke [7], [8] and spinal cord injury [9] and in reducing motor fatigue in MS [10]. In MS, the orthotic effect of FES is well documented as an effective treatment for foot drop [11], [12]. A further three studies involving the lower limb have evaluated the therapeutic effect of FES on strength for pwMS. For example, Hughes et al. [13] showed electrical stimulation augmented a strengthening programme for pwMS who used walking aids. Broekmans et al. [14] compared the effect of adding electrical stimulation to a 20 week progressive resistance training in a mildly disabled population of pwMS. Both interventions showed small improvements in strength but these did not translate to change on functional measures. Modest increases have also been reported in strength, significant improvements in walking tests $(p<0.05)$, and in perceived physical health [15]. Despite this evidence for the effectiveness of FES for the lower limb, to date, no studies have evaluated the effectiveness of FES for the upper extremity. Furthermore, existing studies have employed open-loop control of FES for MS rehabilitation, which do not maximize accuracy or promote voluntray effort, hence limiting the effectiveness of therapy.

Systematic reviews have concluded that robots or electromechanical devices have a beneficial effect on arm impairment and generic ADLs post stroke [16], [17]. In MS, several pilot studies have demonstrated positive effects of robotic training on reducing upper limb impairment and some improvement at the activity level [18]-[23].

This paper examines the feasibility of combining FES and passive robotic support for MS rehabilitation. An advanced control approach termed iterative learning control (ILC) is used to finely adjust the assistance provided to precisely correct performance error in the next attempt of a specific task. ILC uses a biomechanical model of the arm and support system to encourage and support participants' voluntary effort by supplying just enough FES to achieve the movement. ILC is one of the few advanced control approaches to have been successfully applied to reduce upper limb impairments due to chronic stroke, with results showing that combining FES and robotics to enable precise

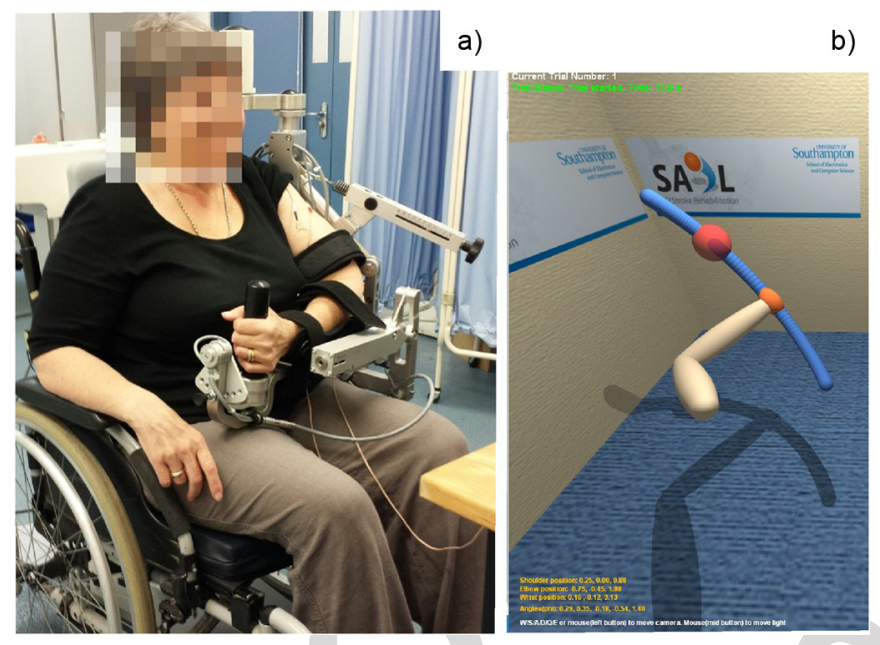

Fig. 2. a) Participant using mechanical support with FES applied using electrodes to her left triceps and anterior deltoid muscles; b) a monitor shows the trajectory task (blue) that the participant needs to follow with their arm (white) with a ball (orange) indicating they are on target for this reaching movement.

assistance of both planar [24] and 3-D upper arm tasks [25] led to improved accuracy in participants' reaching movements. The current system is a further refinement of this technology, embedding new developments in the underlying models and ILC algorithms [26], [27] that enable the tasks to be completed in a manner that more closely matches unimpaired motion. Termed SAIL: Stimulation Assisted by Iterative Learning, it includes a virtual reality (VR) environment depicting a reaching movement on a computer monitor. FES is applied to the triceps and anterior deltoid whilst the arm is supported in a passive robot. The aim of this study is to investigate the feasibility of using the SAIL system to improve arm movement and control for pwMS. This may be due to improving motor control through neuroplastic changes or local muscular changes.

\section{Methods}

\section{A. System Description and Set-Up}

The SAIL system comprises an instrumented passive robotic support, providing kinematic data to a realtime processor that interfaces with custom FES hardware, a VR task display, and a graphical user interface. These elements are shown schematically in Fig. 1 and are described in the following subsections. The participant's screen (located on their hemiplegic side) shows the trajectory to be tracked and a representation of the participant's arm (which mirrors the participant's movements in real-time). The support and trajectory task are depicted in Fig. 2. The display provides the participant with immediate visual feedback and facilitates motivation for the tracking task. The second screen displays a custom graphical user interface which is used by the therapist to select the tasks and adjust the parameters used by the FES control system.

1) Electrical Stimulation: FES electrodes are placed on the anterior deltoid and the triceps muscles. These are connected to a commercially available multi-channel FES device which has been adapted to receive inputs from the real-time control system. The frequency of stimulation is fixed at $40 \mathrm{~Hz}$, with a pulsewidth controlled in real-time by the ILC algorithms. To 


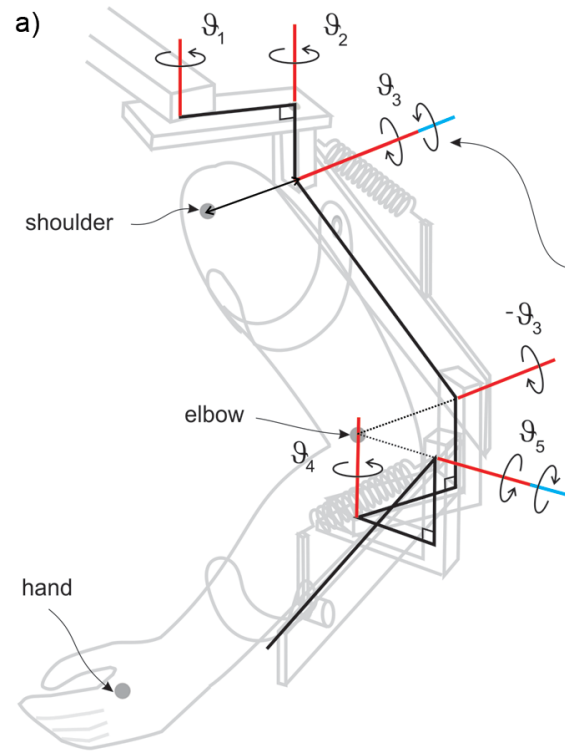

b)

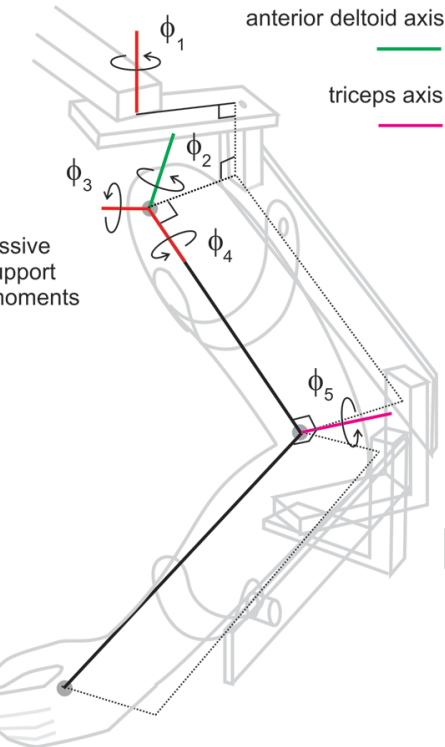

Fig. 3. Kinematic relationships and associated joint angles: a) mechanical support and b) human arm.

identify FES amplitudes for both muscles, the pulsewidth is set at a maximum value and the participant gradually increases the FES amplitude applied to each muscle until they reach a comfortable level that produces movement. Note that although the participant controls the FES amplitude, this is monitored by the therapist. The pulsewidth is then reduced to zero, and the stimulation amplitudes are then fixed for the remainder of each session to ensure participant comfort and safety.

2) Passive Robotic Support: A passive exoskeleton "un-weighing" system supports the participant's arm, providing an adjustable force against gravity via two springs incorporated into the mechanism. Each joint is aligned in either the horizontal or vertical plane, as shown in Fig. 3(a) which also describes the kinematic structure in terms of the measured joint variables, denoted $\boldsymbol{\Theta}=\left[\theta_{1}, \theta_{2}, \theta_{3}, \theta_{4}, \theta_{5}\right]^{\top}$. The participant's hemiplegic arm is loosely strapped into the support mechanism, which is adjusted so that their arm is fully supported off the knee.

3) Biomechanical Model: To promote effectiveness, assistance must precisely coincide with voluntary intention while simultaneously maximizing participant's effort. However, this has not been achieved in MS rehabilitation since existing FES controllers are open-loop. ILC addresses this problem in an optimal framework using a dynamic model of the stimulated arm, and is one of very few model-based upper limb FES control methodologies that has previously been used in upper limb stroke rehabilitation [24], [25]. ILC learns from past experience over repeated attempts of a tracking task in order to embed robustness to disturbance and model uncertainty.

The first stage in constructing a model is to map $\boldsymbol{\Theta}(t)$ to anthropomorphic joint angles. To achieve computationally tractable controllers it was assumed that anterior deltoid contraction produced movement about an axis that is fixed with respect to the trunk. This axis was identified by stimulating the muscle and then fitting a plane to the resulting movement of the elbow in 3-D space using least squares optimization [26] (Fig. 4 shows an example of this axis, which is normal to the

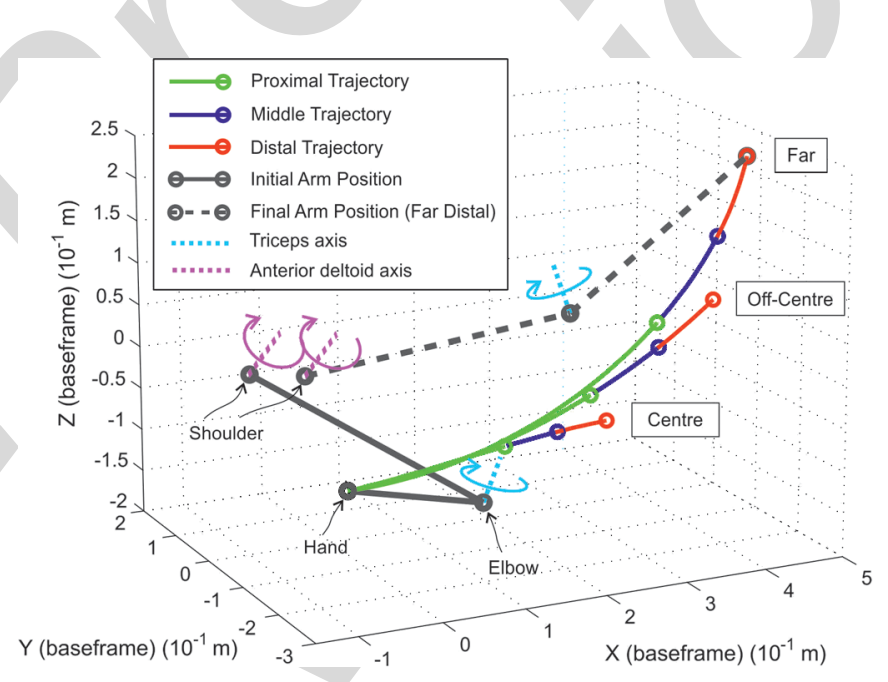

Fig. 4. Location of the arm, axis, and the nine possible trajectories for a participant: made up of direction (center, off center, far) and distance (proximal, middle, and distal). Each task lasted 8-13 s.

fitted plane). The anthropomorphically motivated variables are given by $\boldsymbol{\Phi}=\left[\phi_{1}, \phi_{2}, \phi_{3}, \phi_{4}, \phi_{5}\right]^{\top}$, and are shown in Fig. 3(b). A bijective transformation between coordinate sets is then constructed as $\boldsymbol{\Theta}=f(\boldsymbol{\Phi})$ enabling the combined model of the mechanical support and the human arm to be written as

$$
\boldsymbol{B}(\boldsymbol{\Phi}) \ddot{\boldsymbol{\Phi}}+\boldsymbol{C}(\boldsymbol{\Phi}, \dot{\boldsymbol{\Phi}}) \dot{\boldsymbol{\Phi}}+\boldsymbol{F}(\boldsymbol{\Phi}, \dot{\boldsymbol{\Phi}})+\boldsymbol{K}(\boldsymbol{\Phi})=\boldsymbol{\tau}(\boldsymbol{u}, \boldsymbol{\Phi}, \dot{\boldsymbol{\Phi}})-\boldsymbol{J}(\boldsymbol{\Phi})^{\top} \boldsymbol{h}
$$

where $\boldsymbol{B}(\cdot)$ and $\boldsymbol{C}(\cdot)$ are 5-by-5 inertial and Coriolis matrices, and the non-conservative matrix $\boldsymbol{F}(\cdot)$ accounts for joint stiffness, spasticity, gravity and the unweighing action of the robot. Vector $\boldsymbol{K}(\cdot)$ comprises moments produced through gravity compensation provided by each spring, $\boldsymbol{h}$ is the vector of externally applied force/torque (used only during model identification), and $\boldsymbol{\tau}(\boldsymbol{u}(t), \boldsymbol{\Phi}(t), \dot{\boldsymbol{\Phi}}(t))$ comprises moments generated by the vector, $\boldsymbol{u}(t)$, of stimulation pulsewidths (in microseconds, $\mu \mathrm{s}$ ) applied to each muscle. 


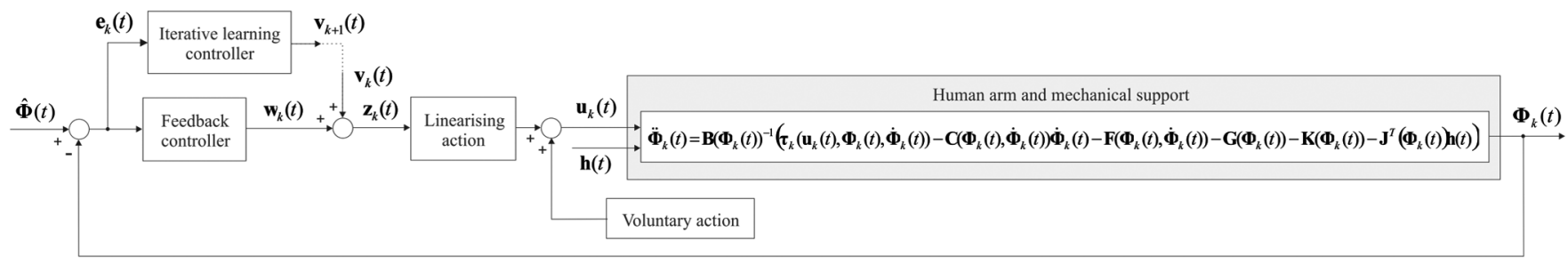

Fig. 5. Combined iterative learning and linearizing feedback FES control scheme showing model of the combined human arm and mechanical support.

4) Workspace and Trajectories: A workspace in which participants can extend to their full range of movement with assistance from FES is established by calculating the spatial coordinates from the highest point in ipsilateral space that the participant can reach when FES is applied to both muscle groups, the lowest point closest to the participant's contralateral thigh, and a front point relating to elbow extension directly in front of the participant. In this way, the workspace corresponds directly to the amount of movement produced by the FES. The reaching tasks comprise nine reaching movements, made up from three different directions and three different distances (see Fig. 4). These are scaled to fit within the workspace so that participants practice reaching within their safe range and exercise tolerance. To ensure each movement closely approximates unimpaired motion, the trajectories are individually customized for each participant using kinematic data collected from 14 unimpaired adults [28]. Reference trajectories for each joint are then extracted, and denoted by $\boldsymbol{\Phi}^{*}(t)$.

5) Control System: The control scheme is shown in Fig. 5 and contains an input-output linearizing feedback controller, together with a feedforward ILC update. The linearizing controller decouples the joints controlled by FES, to produce the form $\boldsymbol{z}_{k}=\left[\boldsymbol{\Phi}_{k, 2}^{(4)}, \boldsymbol{\Phi}_{k, 5}^{(4)}\right]^{\top}$. Here $x^{(i)}$ denotes the $i$ th time derivative of $x, k$ is the trial index, and the additional subscript denotes the component of the vector. Denoting $\boldsymbol{e}_{k}(t)=\boldsymbol{\Phi}^{*}(t)-\boldsymbol{\Phi}_{k}(t)$ as the error joint vector, a standard linear feedback controller with components $\boldsymbol{w}_{k, i}=C_{i}(s) \boldsymbol{e}_{k, i}$, $i \in\{2,5\}$ is then designed such that the roots of $s^{4}+C_{i}(s)=0$ lie in the left half of the $s$-plane. This guarantees stability of the stimulated joint angle dynamics, given by

$$
\begin{gathered}
{\left[\begin{array}{c}
\boldsymbol{e}_{k, 2} \\
\boldsymbol{e}_{k, 5}
\end{array}\right]=\left[\begin{array}{cc}
\frac{s^{4}}{\left(s^{4}+C_{2}(s)\right)} & 0 \\
0 & \frac{s^{4}}{\left(s^{4}+C_{5}(s)\right)}
\end{array}\right]\left[\begin{array}{l}
\hat{\phi}_{2} \\
\hat{\phi}_{5}
\end{array}\right]} \\
-\underbrace{\left[\begin{array}{cc}
\frac{1}{\left(s^{4}+C_{2}(s)\right)} & 0 \\
0 & \frac{1}{\left(s^{4}+C_{5}(s)\right)}
\end{array}\right]}_{G(s)}\left[\begin{array}{l}
\boldsymbol{v}_{k, 1} \\
\boldsymbol{v}_{k, 2}
\end{array}\right] .
\end{gathered}
$$

Note that this also guarantees stability of the joints $\phi_{1}, \phi_{3}, \phi_{4}$ that are not controlled through application of FES, as proven in [26]. Feedback action alone is not sufficient to achieve precise tracking of the reference trajectories. Therefore ILC is employed to update the feedforward signal $\boldsymbol{z}_{k}(t)$ between each attempt at the task, in order to drive FES-assisted components of the tracking error $\boldsymbol{e}_{k}(t)$ to zero. In choosing the stimulation supplied on trial $k+1$, ILC uses the stable, linear, decoupled system (2) to minimize a quadratic objective function of form

$$
\begin{aligned}
J\left(\boldsymbol{u}_{k+1}\right)=\int_{t=0}^{T} & \left\{\left(\boldsymbol{v}_{k+1}(t)-\boldsymbol{v}_{k}(t)\right)^{\top} Q\left(\boldsymbol{v}_{k+1}(t)-\boldsymbol{v}_{k}(t)\right)\right. \\
& \left.+\left[\boldsymbol{e}_{2, k+1}(t), \boldsymbol{e}_{5, k+1}(t)\right] R\left[\begin{array}{l}
\boldsymbol{e}_{2, k+1}(t) \\
\boldsymbol{e}_{5, k+1}(t)
\end{array}\right]\right\} d t
\end{aligned}
$$

where $T$ is the duration of the task. Through selection of positive-definite weighting matrices $Q$ and $R$, this objective function allows the designer to balance accuracy of task completion with the amount of FES applied to assist the participant's movement. The cost function (3) is solved using the update algorithm

$$
\boldsymbol{v}_{k+1}=\boldsymbol{v}_{k}+G^{*}(s)\left(I+G(0073) G^{*}(s)\right)^{-1}\left[\begin{array}{l}
\boldsymbol{e}_{k, 2} \\
\boldsymbol{e}_{k, 5}
\end{array}\right]
$$

where $G^{*}(s)$ is the adjoint of operator $G(s)$. Full details of the algorithm implementation, together with theoretical robustness and convergence properties, are given in [26] and [29].

6) Model Identification: The participant's upper arm and forearm lengths are measured and combined with the joint axis description of Section II-A3 to supply the kinematic relationship between the arm position in Cartesian space and the vector of joint angles, $\boldsymbol{\Phi}(t)$, as well as the system Jacobian matrix, $\boldsymbol{J}(\boldsymbol{\Phi})$. Next a six-axis sensor is attached to the extreme link of the robotic support and is held stationary while FES is applied to each muscle in turn. The resulting force $\boldsymbol{h}(t)$ recorded by the sensor is then related to the torque vector developed by the muscles $\boldsymbol{\tau}(\cdot)$ via the Jacobian matrix. A Hammerstein structure comprising a static isometric recruitment curve combined with linear activation dynamics is employed to model the response of each muscle to applied FES. This provides the dynamic relationship $\boldsymbol{\tau}(\boldsymbol{u}(t), \boldsymbol{\Phi}(t), \dot{\boldsymbol{\Phi}}(t))$, with details of the optimization procedure and validation of fitting accuracy given in [30]. Typical fitting results are shown in Fig. 6, where the stimulation applied to each muscle is a triangular ramp function. The terms $\boldsymbol{B}(\boldsymbol{\Phi}(t)), \boldsymbol{C}(\boldsymbol{\Phi}(t), \dot{\boldsymbol{\Phi}}(t))$, and $\boldsymbol{F}(\boldsymbol{\Phi}(t), \dot{\boldsymbol{\Phi}}(t))$ are all identified by applying FES to the muscles while moving the arm using the sensor, and using an optimization procedure on the resulting signals $\boldsymbol{h}(t)$ and $\boldsymbol{u}(t)$. In model validation experiments, the model has been found to fit experimental joint angle data sets with an accuracy which typically exceeds $90 \%$. Full details of the procedure used, as well as detailed fitting results, are given in [26] and [31]. Due to time constraints $\boldsymbol{B}(\cdot), \boldsymbol{C}(\cdot)$, and $\boldsymbol{F}(\cdot)$ were identified in a pilot session and then used throughout the intervention. 


\section{B. Clinical Test Design}

A proof-of-concept study with pwMS was undertaken to determine the effect on upper limb function of 18 one-hour sessions using the SAIL system to perform tracking tasks. All participants attended one pilot, two assessment, and eighteen intervention sessions at the University of Southampton, Faculty of Health Science (FoHS). The intervention was carried out by an experienced physiotherapy researcher. Two independent physiotherapists, unblinded to the intervention, performed the clinical assessments; the same physiotherapist performed both the pre and post assessment per participant. A semi-structured interview of participants' experience of using the SAIL system was completed by a health psychologist after the final assessment.

\section{Participants}

Following ethical approval (FoHS ETHICS-2013-5429) and written informed consent, a convenience sample of five pwMS was recruited from local MS society organizations around Southampton. Inclusion Criteria were: 1) confirmed diagnosis of MS; 2) impaired upper limb such that they were unable to achieve or maintain their arm at $90^{\circ}$ shoulder flexion, predominantly due to weakness; 3) FES produced movement without undue discomfort whilst the pwMS was seated with their arm in the robot; 4) could communicate effectively; 5) able to give informed consent. Exclusion Criteria were: 1) current relapse or commencement of steroids within 28 days of assessment; 2) marked intention tremor; 3) marked spasticity with Modified Ashworth $>2$ in shoulder flexors; 4) absent sensation in electrode sites; 5) any active device implant; 6) any metal implant in upper limb; 7) uncontrollable epilepsy; 8) pregnancy; 9) any serious or unstable medical or psychological condition or cognitive impairment; 10) current participation in another upper limb physical rehabilitation study. FES is an internationally recognized treatment for foot-drop in pwMS and stroke although there are specific contra-indications or risks when using FES; these formed part of our exclusion criteria. Recruitment occurred between June and September 2013. All participants completed the study and complied with the protocol.

\section{Intervention Sessions}

Each participant identified their most impaired arm. This was confirmed by the ARAT and FMA results, and was the arm treated. FES was applied as described in Section II-A, and the participant's arm was placed into the support mechanism. The level of arm support was personalized to ensure each person achieved their optimal range of movement. A pilot session was undertaken to identify the model and tune parameters in the ILC algorithms, a process lasting about $5 \mathrm{~min}$. The 18 intervention sessions then followed, during each of which the workspace was identified and the participant then practiced a minimum of six trajectories, each repeated six times, with a rest period of 2-10 s between each attempt. This provided between 18-33 min of treatment time. Participants were verbally encouraged during the reaching practice. The number of trajectories practiced increased during the intervention period to between eight and eleven according to participants' progress, fatigue, and motivation. Similarly, as participants progressed through the intervention, the level of support from the passive robot was gradually decreased according to their exercise tolerance. To assess unassisted performance, at the beginning and end of every session each participant tracked the same four different trajectories only once, with no FES.

\section{E. Outcome Measures}

The focus of this study was on the feasibility of the SAIL and whether pwMS could tolerate it. The primary outcome measures were change in amount of FES delivered and accuracy of task tracking over the treatment period. Secondary outcome measures evaluated clinical changes to the upper limb according to the impairment and activity domain of the ICF and were measured before treatment and within one week after the treatment period. The clinical outcome measures were: Action Research Arm Test (ARAT) [32]-[35]; Nine Hole Peg Test (9HPT) [35]-[37]; Manual Ability Measure (MAM-36) [38], [39]; and Fugl-Meyer Assessment (FMA) [35], [40]-[42]. The FMA, valid and reliable for assessing arm impairment in pwMS [43] and used to assess arm movement in pwMS [35], [44], measures motor control mainly at impairment level whereas the ARAT measures upper limb function using standardised activities. The MAM-36 is a valid measure of a person's perceived ability to use his/her hands and is meaningful to participants [39]. The MAM-36 raw score was converted to the MAM-36 measure using the conversion table [39]. The 9HPT is sensitive in assessing upper limb functional status change in pwMS [35], [37] and is part of MS composite score [45] where the task is to be completed within $300 \mathrm{~s}$. The Rivermead Perception Assessment Battery (RPAB) figure ground, 3-D copying and cancellation tests were used to assess 2-D, 3-D, and neglect, respectively [46], so that participants could be adequately supported during the intervention as the VR environment required visual perception.

A structured interview using a 26 item questionnaire based on one used in people with stroke [47] occurred immediately after the post-intervention assessment or later by telephone. Both open and closed questions were included to obtain an understanding of the system's effectiveness and usability; improvements required; and general questions about the intervention. Some of the open questions encouraged yes/no replies followed by an explanation: the remainder of the questions were completely open. Closed questions required a Likert-response indicating the extent of agreement (see Appendix A). The interview was purposely kept short, taking approximately $30 \mathrm{~min}$, although participants were encouraged to elaborate as much as possible. A psychologist who was not involved with delivering the intervention undertook the interview to encourage openness from participants.

\section{F. Statistical Analysis}

The clinical outcome measures: FMA; ARAT; MAM and 9HPT; measured at baseline and after the intervention, were analysed in SPSS v19 using the Wilcoxon signed-rank test. Conforming to prior studies [24], [48], the performance of tracking with FES (assisted) and without FES (unassisted) 

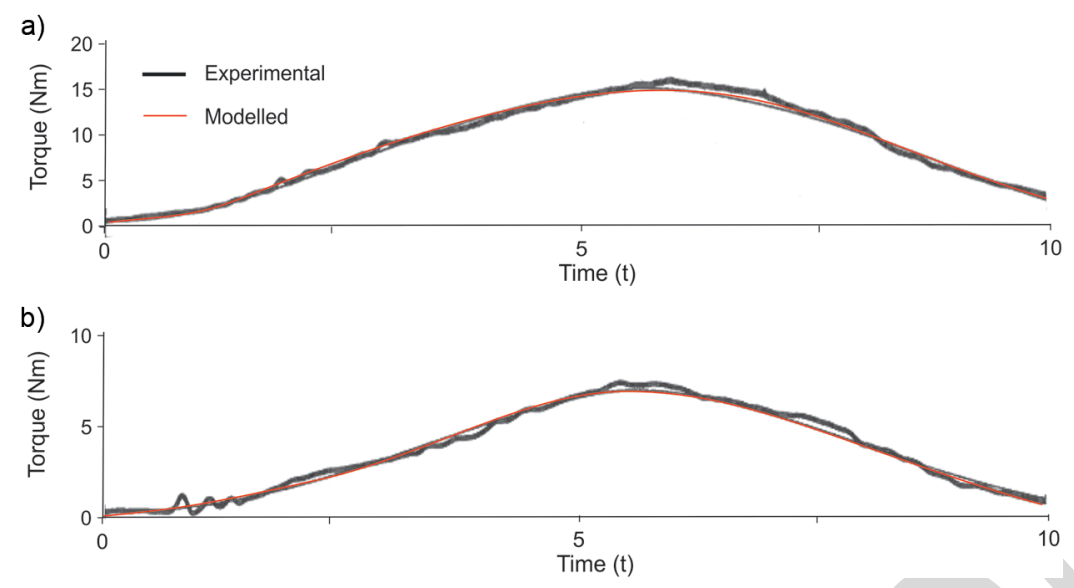

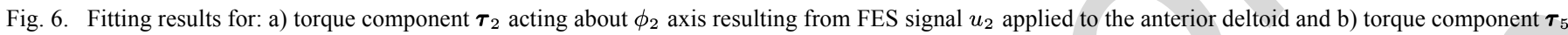
acting about $\phi_{5}$ axis resulting from FES signal $u_{5}$ applied to the triceps.

was analyzed per participant for each of the 18 sessions by calculating best-fit linear regression slopes of performance for each task. Two-tailed t-tests were applied, and the level of significance for all tests was set at $p<0.05$. The $95 \%$ confidence intervals were also calculated to provide a measure of how precisely the true mean can be bounded given the limited sample size. Tracking performance was calculated by taking the 2-norm of the error between arm position and target trajectory and normalizing it as follows: let $\boldsymbol{e}_{i, k}(t)$ denote the $i$ th element of vector $\boldsymbol{e}_{k}(t)$ at time " $t$ ", and similarly $\boldsymbol{\Phi}_{i}^{*}(t)$ the corresponding reference, then tracking performance of the $i$ th joint is given by

$$
100 \times\left(1-\sqrt{\frac{\int_{0}^{T} \boldsymbol{e}_{k, i}(t)^{2}}{\int_{0}^{T} \boldsymbol{\Phi}_{i}^{*}(t)^{2}}}\right) .
$$

A value of 100 indicated perfect tracking and 0 corresponded to no movement.

\section{G. Structured Interview}

Closed questions eliciting Likert responses were totalled and are presented in Appendix A.

\section{RESULTS}

Characteristic data for the five female participants who took part in the intervention are given in Table I. One participant with shoulder subluxation received additional supraspinatus FES to increase glenohumeral congruency and her reaching tasks were kept within a pain free range to avoid biomechanical impingement. All participants were able to increase the number of reaching tasks practised per session to between eight and eleven reaching tasks. All participants, except one, were able to receive less support from the passive robot during the reaching movements: the one participant's biceps tone increased on reducing the support so her support was kept constant. No serious adverse events were reported during the intervention period. One participant had 3-D visual impairment identified by the RPAB 3-D copying test $(4 / 24)$, and here the therapist
TABLE I

SOCIO-DEMOGRAPHIC CHARACTERISTICS OF PARTICIPANTS $(n=5)$

\begin{tabular}{lccccc}
\hline Pt Id & MS1 & MS2 & MS3 & MS4 & MS5 \\
\hline Age (years) & 60 & 40 & 61 & 51 & 61 \\
Type of MS & SPMS & RRMS & PPMS & SPMS & SPMS \\
Years MS diagnosed & 34 & 4 & 16 & 14 & 31 \\
Female/Male & $\mathrm{F}$ & $\mathrm{F}$ & $\mathrm{F}$ & $\mathrm{F}$ & $\mathrm{F}$ \\
Side treated & $\mathrm{L}$ & $\mathrm{R}$ & $\mathrm{L}$ & $\mathrm{L}$ & $\mathrm{R}$ \\
Original dominant hand & $\mathrm{R}$ & $\mathrm{R}$ & $\mathrm{R}$ & $\mathrm{R}$ & $\mathrm{R}$ \\
Full time wheelchair user & $\mathrm{Y}$ & $\mathrm{N}$ & $\mathrm{Y}$ & $\mathrm{Y}$ & $\mathrm{Y}$ \\
Glasses & $\mathrm{Y}$ & $\mathrm{N}$ & $\mathrm{Y}$ & $\mathrm{Y}$ & $\mathrm{Y}$ \\
\hline
\end{tabular}

Pt Id - participant identification, SPMS - secondary progressive MS, RRMS - relapse-remitting MS, PPMS - primary progressive MS, $\mathrm{F}$ - female, $\mathrm{M}$ - male, $\mathrm{L}$ - left, $\mathrm{R}$ - right, $\mathrm{Y}$ - yes, $\mathrm{N}$ - no.

assisted in directing the participant's arm movement during the tracking task. Her score of $12 / 24$ on the $3-\mathrm{D}$ copying test on completion of the intervention session suggests some 3-D learning may have occurred. All the other participants scored $\geq 18 / 24$ (normal perceptual range) [46] and were able to track independently. A future study should consider excluding 3-D visually impaired participants, ensuring the training is independent of the therapist.

\section{A. Assisted Tracking Performance}

Performance was calculated for the final attempt of every tracking task. These performances were then averaged to calculate the tracking performance and the maximum amount of FES provided. Data in Fig. 7(a) and (b) show improved accuracy of tracking performance at both the shoulder and elbow and Fig. 7(c) and (d) show the percentage maximum FES required to improve participants' tracking reduced over the treatment period. Table II shows the $p$-value and mean slope of the tracking performance and percentage maximum FES, which was statistically significant for each muscle group: triceps (elbow) and anterior deltoid (shoulder). The mean tracking performance slopes (elbow 0.71, shoulder 1.31) correspond to an average improvement over 18 sessions of $12.8 \%$ and $23.6 \%$ for the elbow and shoulder, respectively. The mean percentage maximum FES slopes (elbow -2.6805, shoulder -2.7143) correspond to an average reduction over 18 sessions of $49.2 \%$ and $48.8 \%$ for the elbow and shoulder, respectively. This suggests 
a)
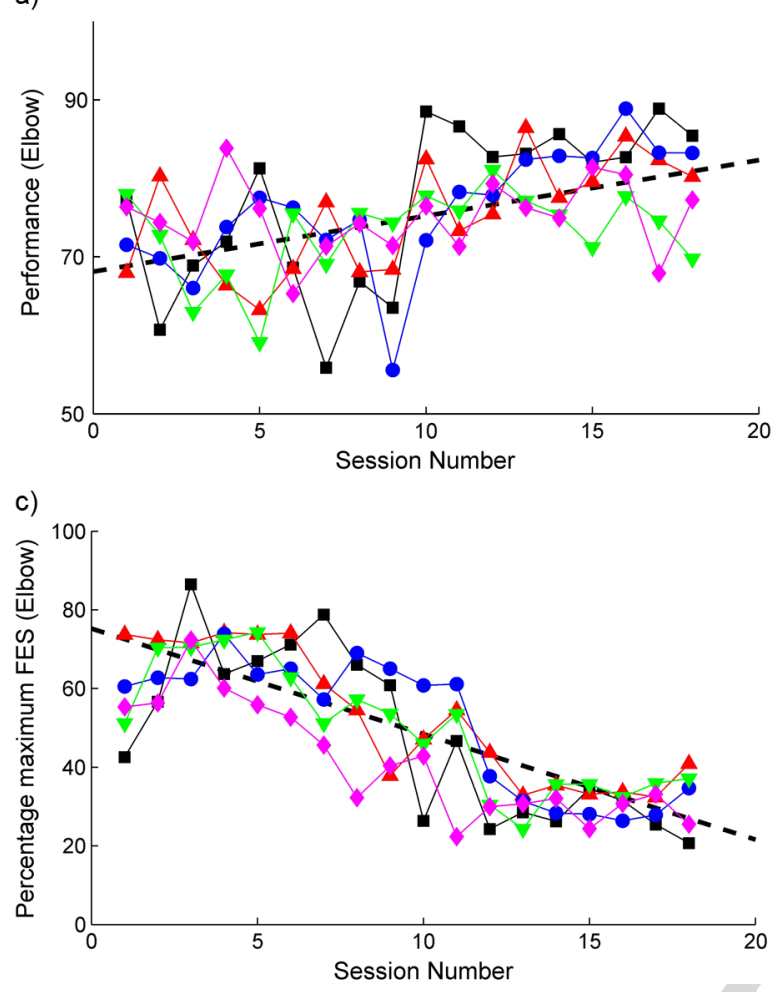

b)

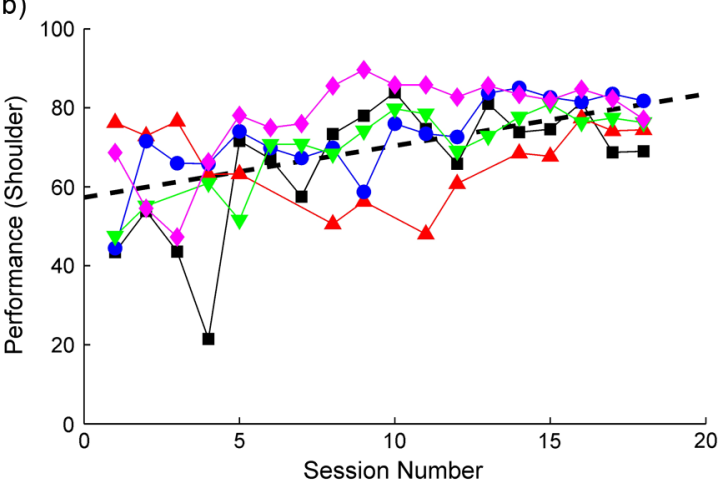

d)

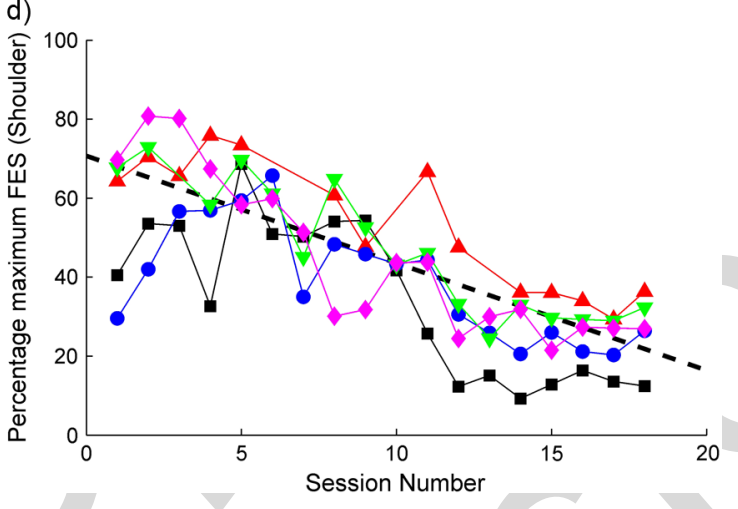

Fig. 7. Assisted task tracking accuracy and amount of FES, averaged over all tasks: a) accuracy of task tracking at the elbow; b) accuracy of task tracking at the shoulder; c) amount of FES applied at the elbow; and d) amount of FES applied at the shoulder. Mean of individual slopes shown by dotted line.

TABLE II

Tracking Performance Measures at the Elbow and Shoulder SHOWing the Mean SLOPE AND $p$-VAlue of the Best Fit Linear REGRESSION LINES COLLAPSED ACROSS PARTICIPANTS FOR ASSISTED AND UNASSISTED TASKS

\begin{tabular}{lcccc}
\hline Task & Elbow & \multicolumn{3}{c}{ Shoulder } \\
\cline { 2 - 5 } & $\begin{array}{l}\text { Mean } \\
\text { slope }\end{array}$ & $\begin{array}{c}p \text {-value } \\
\text { CI }\end{array}$ & $\begin{array}{c}\text { Mean } \\
\text { slope }\end{array}$ & $\begin{array}{c}p \text {-value } \\
\text { CI }\end{array}$ \\
\hline Assisted & & & & \\
Tracking perf. \% & 0.71 & 0.027 & 1.31 & 0.015 \\
& & $(0.13,1.28)$ & & $(0.42,2.20)$ \\
\% maximum ES & -2.68 & 0.000 & -2.71 & 0.000 \\
& & $(-3.03,-2.33)$ & & $(-3.38,-2.04)$ \\
Tracking perf. \%/\% max ES & 0.12 & 0.000 & 0.19 & 0.021 \\
& & $(0.08,0.16)$ & & $(0.04,0.32)$ \\
Unassisted tracking perf. \% & & & & \\
Centre proximal & & & & \\
& 2.37 & 0.006 & 6.24 & 0.065 \\
Centre distal & & $(1.10,3.62)$ & & $(-0.62,13.10)$ \\
& 1.91 & 0.011 & 6.31 & 0.051 \\
Off-centre middle \%/\% max ES & 2.21 & $(0.72,3.10)$ & & $(-0.08,12.69)$ \\
& & $(0.61,3.81)$ & 3.75 & 0.017 \\
Far distal & 2.33 & 0.006 & 3.33 & $(1.09,6.40)$ \\
& & $(1.08,3.58)$ & & $(1.72,4.93)$ \\
\hline
\end{tabular}

Note: The small slope values are due to the different units in the axes. CI denotes $95 \%$ confidence interval.

that less FES was required to produce more accurate movement over the treatment period. This was confirmed when the slope of the tracking performance percentage was divided by the slope of the percentage maximum FES for each participant. Taking the mean over participants yields a statistically significant slope (elbow mean slope $=0.12, p<0.001$, shoulder mean slope $=0.19, p<0.05$ ): see last line in Table II under assisted.

\section{B. Unassisted Tracking Performance}

Tracking performance of the four tasks, unassisted by FES, that were completed at the beginning and end of each session was calculated, and an average taken for each task. Figs. 8 and 9 show tracking performance at the elbow and shoulder, respectively, over the course of the intervention. Statistically significant improved accuracy in tracking performance for all four tracking tasks was identified across all participants at the elbow and for two tasks at the shoulder. Table II shows the $p$-value and mean slope of these unassisted tasks. The positive mean slopes of all the unassisted tasks correspond to increases in performance of between $34.38 \%$ and $113.58 \%$ over the intervention period.

\section{Clinical Outcome Measures}

All clinical outcome measures improved after the intervention period (see Fig. 10). Improvements were seen at: impairment level, FMA increased by 6 (5.5) points from 44.8 (5.8) to 50.8 (8.2) out of a maximum score of 66 ; perceived ability, MAM-36 measure [39] increased by 3.6 (8.1) from 46.8 (10) to 50.4 (8); and actual ability in arm function, ARAT increased by 0.6 (3.7) points from $45.6(10.5)$ to 50.8 (8.2) out of a maximum score of 57. The 9HPT time decreased from 145.3 (96) to 116.3 (88). Only the proximal arm section of the FMA, where the intervention was aimed and which measures at the impairment level of the ICF, identified statistically 
TABLE III

Results for the Clinical Outcome Assessments Showing Baseline and Post-Intervention Scores for the Five Participants

\begin{tabular}{|c|c|c|c|c|c|c|c|c|c|}
\hline $\mathrm{Pt} \mathrm{ID}^{1}$ & & MS1 & MS2 & MS3 & MS4 & MS5 & Mean (SD) & p-value & $\%$ change $^{2}$ \\
\hline MAM-36 \% ${ }^{3}$ & $\begin{array}{l}\text { Baseline } \\
\text { Post }\end{array}$ & $\begin{array}{l}40 \\
57\end{array}$ & $\begin{array}{l}56 \\
57\end{array}$ & $\begin{array}{l}59 \\
54\end{array}$ & $\begin{array}{l}37 \\
39\end{array}$ & $\begin{array}{l}42 \\
45\end{array}$ & $46.8(9.99)$ & 0.345 & 3.6 \\
\hline ARAT $(57)^{4}$ & $\begin{array}{l}\text { Baseline } \\
\text { Post }\end{array}$ & $\begin{array}{l}56 \\
53\end{array}$ & $\begin{array}{l}57 \\
57\end{array}$ & $\begin{array}{l}33 \\
33\end{array}$ & $\begin{array}{l}42 \\
41\end{array}$ & $\begin{array}{l}40 \\
47\end{array}$ & $\begin{array}{c}45.6(10.50) \\
46.2(9.55)\end{array}$ & 1.0 & 1.05 \\
\hline FMA $(66)^{4}$ & $\begin{array}{l}\text { Baseline } \\
\text { Post }\end{array}$ & $\begin{array}{l}54 \\
64\end{array}$ & $\begin{array}{l}46 \\
50\end{array}$ & $\begin{array}{l}44 \\
43\end{array}$ & $\begin{array}{l}41 \\
45\end{array}$ & $\begin{array}{l}39 \\
52\end{array}$ & $\begin{array}{l}44.8(5.81) \\
50.8(8.23)\end{array}$ & 0.078 & 9.09 \\
\hline FMA proximal arm $(36)^{4,5}$ & $\begin{array}{l}\text { Baseline } \\
\text { Post }\end{array}$ & $\begin{array}{l}30 \\
35 \\
\end{array}$ & $\begin{array}{l}23 \\
28 \\
\end{array}$ & $\begin{array}{l}20 \\
21\end{array}$ & $\begin{array}{l}18 \\
23\end{array}$ & $\begin{array}{l}21 \\
33\end{array}$ & $\begin{array}{l}22.4(4.62) \\
28.0(6.08)\end{array}$ & 0.039 & 15.56 \\
\hline FMA distal arm $(30)^{4,6}$ & $\begin{array}{l}\text { Baseline } \\
\text { Post }\end{array}$ & $\begin{array}{l}24 \\
29\end{array}$ & $\begin{array}{l}23 \\
22\end{array}$ & $\begin{array}{l}24 \\
22\end{array}$ & $\begin{array}{l}23 \\
22\end{array}$ & $\begin{array}{l}18 \\
19\end{array}$ & $\begin{array}{l}22.4(2.5) \\
22.8(3.7)\end{array}$ & 0.891 & 1.33 \\
\hline 9HPT $(300 \text { secs })^{7}$ & $\begin{array}{l}\text { Baseline } \\
\text { Post }\end{array}$ & $\begin{array}{c}64 \\
229\end{array}$ & $\begin{array}{l}220 \\
143\end{array}$ & $\begin{array}{c}237 \\
43\end{array}$ & $\begin{array}{l}\text { utc }^{8} \\
\text { utc }^{8}\end{array}$ & $\begin{array}{l}70 \\
78\end{array}$ & $\begin{array}{l}145.3(96.39) \\
116.3(87.91)\end{array}$ & 0.465 & 8.17 \\
\hline
\end{tabular}

${ }^{1}$ participant identification. ${ }^{2}$ change in score divided by maximum possible score. ${ }^{3}$ motor ability measure with 36 items converted to percentage using Rasch analysis tables [39]. ${ }^{4}$ maximum score in brackets. ${ }^{5}$ proximal arm section of FMA encompassing Shoulder-Elbow-Forearm. ${ }^{6}$ distal arm section of FMA encompassing the wrist and hand. ${ }^{7}$ nine hold peg test measured in seconds. ${ }^{8}$ unable to complete.
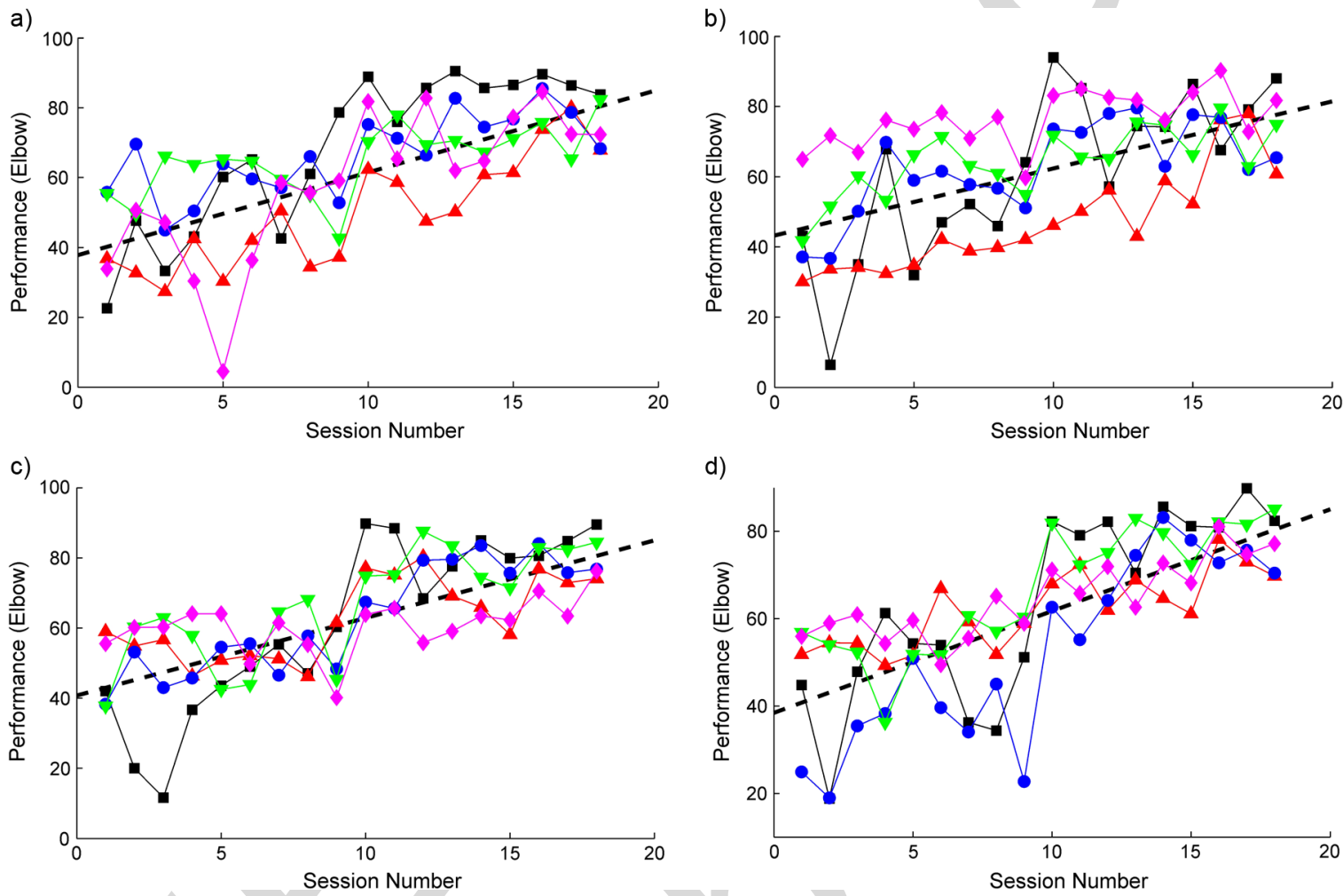

Fig. 8. Unassisted task tracking accuracy at the elbow. Each participant's performance is shown as a function of session for the four tracking tasks, unassisted by FES, before/after the intervention. The four tracking tasks are: a) center-proximal, b) center-distal, c) off-center-middle, and d) far-distal.

significant improvement $(z=-2.06, p=0.039)$ with an improvement of 5.6 (3.9) points from 22.4 (4.1) to 28 (5.4) out of a possible 36 points. This contrasts to the minimal 0.4 (2.7) point improvement out of a possible 30 points relating to the distal arm section of the FMA. Fig. 10(a) and (b) depict this. Only the area trained, the proximal arm, improved which suggests that specificity in training is required.

\section{Questionnaire}

All participants reported that now they were more aware of their affected arm, it did not feel weaker or tighter as a result of the intervention and that they were reaching out more easily. Two participants reported that they could now cut food using both a knife and fork whereas prior to the intervention, their carer would do this. All participants found two handed tasks easier such as folding clothes, cutting bread and personal hygiene (washing face). They all found the intervention enjoyable and it easy to understand what to do. All participants wanted additional muscles stimulated, wanted the intervention to continue, and would recommend the intervention to other pwMS. No participants found the FES particularly uncomfortable. Totals of Likert responses can be found in Appendix A.

\section{DISCUSSION}

The main aim of this study was to determine the feasibility and effectiveness of using the SAIL system for pwMS; this is the first time passive robotic arm support has been combined with FES to improve movement quality for this user group, and the 
a)

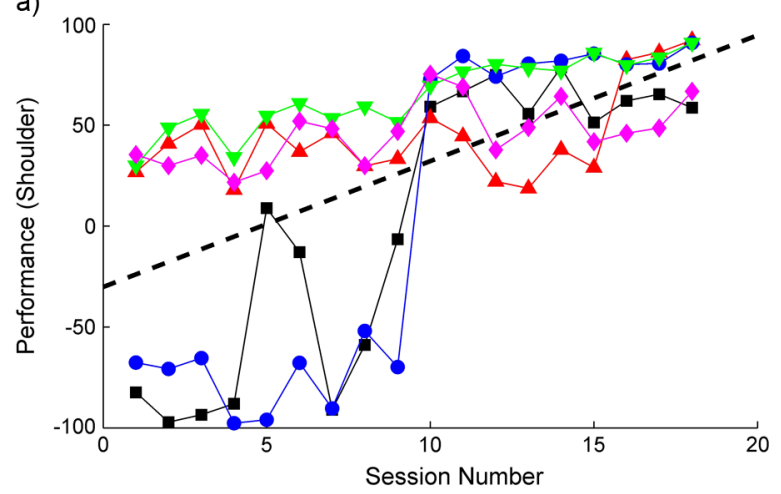

c)

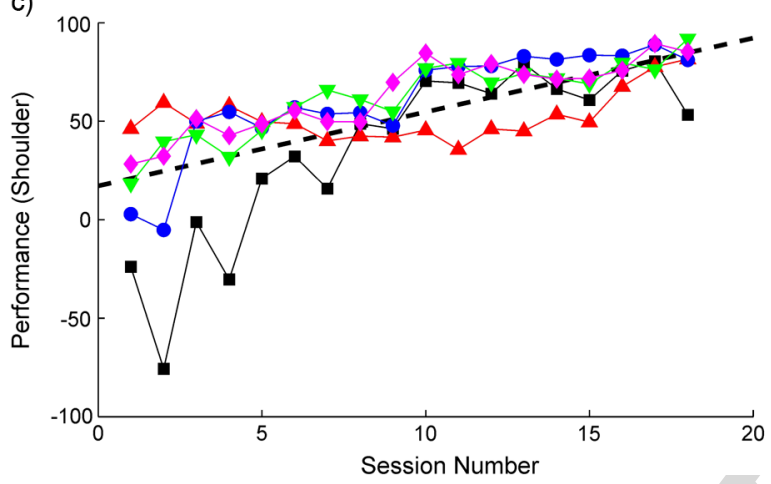

b)

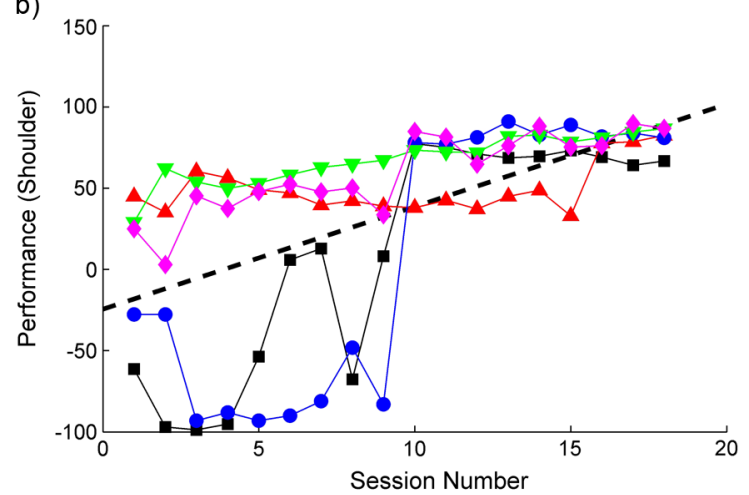

d)

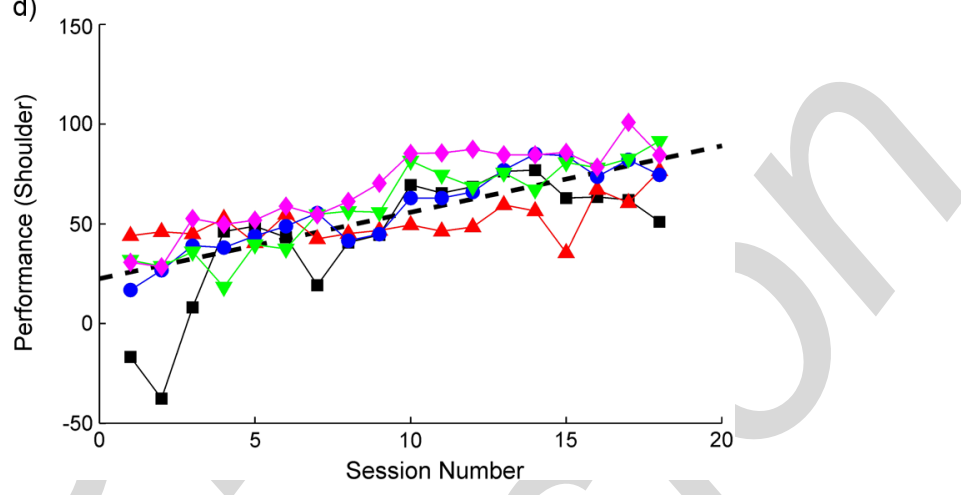

Fig. 9. Unassisted task tracking accuracy at the shoulder. Each participant's performance is shown as a function of session for the four tracking tasks, unassisted by FES, before/after the intervention. The four tracking tasks are: a) center-proximal, b) center-distal, c) off-center-middle, and d) far-distal.

first use of advanced model-based controllers to promote accuracy and voluntary effort. pwMS tolerated the intervention with no adverse effects and attended all 18 treatment sessions over a 10 week period. An improvement in arm awareness, better arm control and daily usage of their impaired arm was reported. Three important findings were identified following the intervention: improved tracking performance during the unassisted task; reduced FES required during the assisted tasks and an improvement in the proximal arm section of the FMA. Furthermore there were clear trends for clinical improvement in most measures by most patients.

The implication of improved tracking performance during assisted tasks over the treatment period, while less ILC mediated FES was required to achieve this, suggests that the participant's voluntary effort (muscle power and arm control) increased. Similarly, as participants progressed through the treatment sessions they were able to make more accurate reaching movements with no FES applied. All participants improved in the impairment domain of the ICF, measured by the proximal arm section of the FMA, where statistical significance was identified at the shoulder and elbow active movement control where the intervention was aimed. This is a new finding that indicates that movement quality improved following training. As with all statistical tests using small sample sizes, these conclusions must be treated with caution as they necessarily have limited power. The results however demonstrate the feasibility of the SAIL system with pwMS and suggest there is treatment potential for this novel system to aid recovery. These SAIL results are comparable to previous work undertaken on persons with stroke [24], [48]. Other robotic studies on pwMS [18], [20] have iden- tified improvements on arm capacity tests but this is the first study to show improvements in movement quality.

These findings are consistent with Lamers et al. [35] which identified that the FMA, or impairment outcome measurement, could predict changes in actual performed movements in daily life better. On group level, the 9HPT and ARAT showed no significant improvement but general trends were evident; two pwMS had large improvements in the 9HPT. Other studies of FES on the lower limb in pwMS [13], [14] also identified improvements at impairment rather than activity level. An explanation by Deutsch [5] is that improvements in impairment imply recovery has occurred rather than there being compensatory movement.

Fatigue is one of the most common symptoms in pwMS, but exercise has a positive effect on fatigue [49] and results from a pilot study combining exercise and FES [50] suggest reduced muscle fatigue. However, it should be noted that not all pwMS present with abnormal muscle fatigue [51]. Our results showed that all participants were able to increase the amount of exercise performed per session, indicating a possible improvement in muscle fatigue, but a future larger study should confirm this.

Progressive MS follows a predictable path with a direct relationship between duration of disease and increase in disability irrespective of whether this is PPMS or SPMS [52]. Two participants, MS1 and MS4, reported an exacerbation of their MS part way through the intervention period specifically relating to their impaired hand. MS4 had increased parasthesia (finger tips to elbow) and reduced finger movement (which was observed) directly following flu-like symptoms, and MS1 had altered temperature sensation. This increase in disability 
a) Fugl-Meyer (FMA) - Proximal Arm

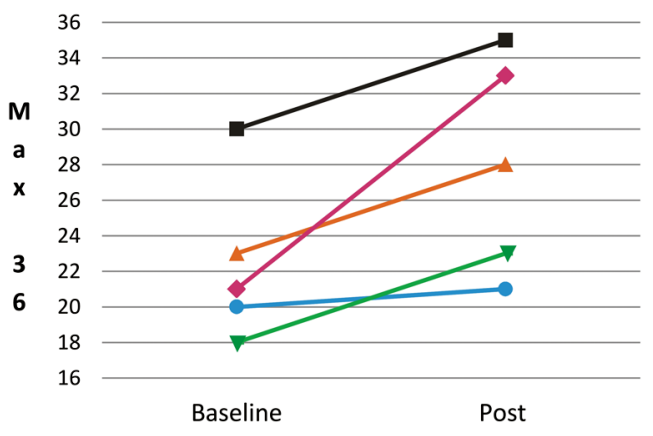

c) 9 Hole Peg Test (9HPT)

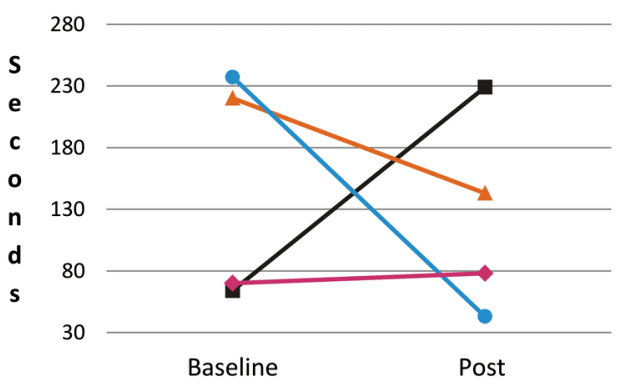

b) Fugl-Meyer (FMA) - Distal Arm

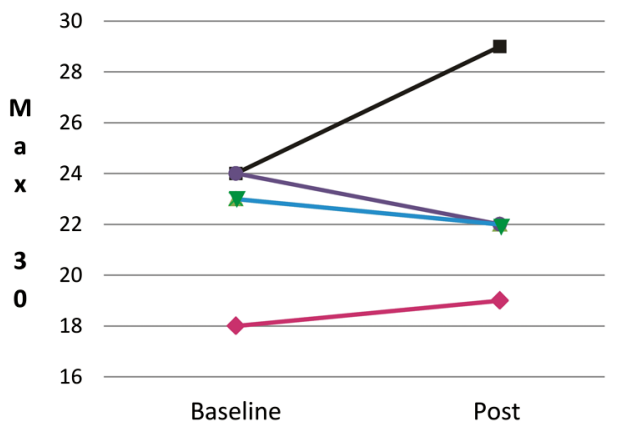

d) Manual Ability Measure (MAM-36)

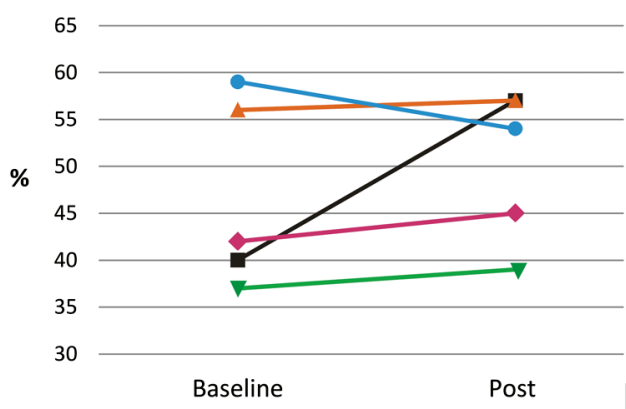

e) Action Research Arm Test (ARAT)

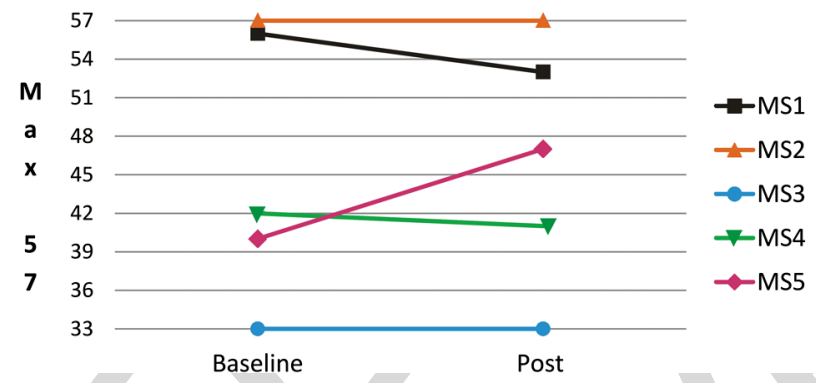

Fig. 10. The clinical outcome measures: a) the proximal arm section of the FMA (maximum value 36), b) the distal arm section of the FMA (maximum value 30), c) 9HPT, d) MAM-36, and e) ARAT showing the baseline and post assessment results for each participants.

is an expected consequence of progressive MS [52] and may explain anomalies in the clinical tests, 9HPT and ARAT. As current evidence supports physical exercise in pwMS, with active people having fewer relapses [53], it is unlikely that the intervention caused these changes. Both these participants had slightly reduced scores on the ARAT and took longer to complete the 9HPT after training: one unable to complete it due to finger flexor spasms and the other dropped her peg. Both the ARAT and 9HPT measure the upper limb in the activity domain of ICF but integrate fine pinch function/manual dexterity into the test, so any deterioration in participants' ability to pinch would adversely affect the score. SAIL did not stimulate hand/wrist muscles, working purely on the shoulder and elbow which may explain the minimal change in the ARAT, so it was encouraging to identify that these same two participants showed large improvements in the proximal arm section of the FMA and in the MAM-36. This suggests that their shoulder and elbow control and movement improved following the intervention even though their MS had worsened. The ARAT may not measure actual functions pwMS perform, explaining why their MAM-36 improved but not the ARAT. In view of this, the authors would recommend using another measure such as the Wolf Motor Function Test to assess improvements in proximal control.

\section{A. Participant Comments}

Comments from all participants regarding the best aspects of the intervention included: "...felt I regained control of the MS rather than MS controlling me. ..”; “. . . seeing what an impact it had on arm and the benefits of it..."; "...being able to move arm and realize that although I have progressive MS things can improve provided given the right intervention..."; "... improvement in physical abilities from it. .."; and "... arm is definitely stronger now and can do more things with it...". All participants indicated that now they were able to reach out more easily and two participants now could cut up their food independently with a knife and fork. The comments from this feasibility study serve to elucidate that even in a progressive disease such as MS, improvements in upper limb function resulting from this intervention were noticed by all participants. More importantly the upper limb improvements had translated into their daily life and were meaningful to them: improvements 
that the ARAT could not detect. Useful feedback from participants about using the SAIL system can be used in future enhancements.

\section{B. Limitations of the Study}

Limitations included a small sample size, unblinded clinical evaluators, no control group and lack of a follow up (due to time constraints), signifying that the findings should be interpreted with caution. We cannot generalize the findings from this small group given that it is well-known that pwMS can present with a wide variety of symptoms including fatigue, weakness, spasticity, and sensory loss. However, we note that the system was well tolerated by all members of the participant group which encompassed various levels of disability.

This was a proof of concept study that motivates and lays the groundwork for a future study in terms of feasibility, participation rates, resource requirements and sample estimation data. The sufficiently powered future study is expected to have three arms: a control group receiving no intervention; the SAIL system; and mechanical support alone. This would identify what learning results from practicing a task and clarify the extent to which the SAIL system assists with reducing impairment, thus highlighting whether SAIL provides an effective treatment for MS upper limb impairment. The future study's sample should focus specifically on arm dysfunction and exclude participants with cerebellar disorders. As the clinical outcome measures incorporate the entire arm with the hand/wrist as an essential component, a future study should include stimulation of the wrist extensors/flexors so that therapy is delivered to the entire arm including the wrist/hand. It may also be beneficial to practice functional tasks involving manipulation of objects, in addition to the reaching tasks. By adding more functional tasks such as pressing a light switch, it is possible that improvements might better translate into everyday tasks.

\section{CONCLUSION}

This study demonstrated the feasibility of using advanced control approaches combined with FES and robotic support to improve arm movement for pwMS. There was excellent adherence by pwMS to the intervention and no side effects were reported. The intervention resulted in improvements in reaching accuracy with and without FES and reduced impairment in the proximal arm. As these technologies are developed, they will allow an increased intensity of rehabilitation to be delivered with minimal therapist input. The improvements identified by the outcome measures combined with the positive feedback from all participants concerning their improved arm movement and control should not be ignored. This study included a novel combination of interventions that warrants further investigation.

APPENDIX A

SEMI-STRUCTURED INTERVIEW QUESTIONS AND LIKERT RESPONSE [47]

See Table IV.
Table IV

Semi-STRUCtured INTERVIEW QueStions AND LiKert Response [47]

\begin{tabular}{|c|c|c|c|c|c|c|}
\hline \multirow[t]{2}{*}{ Category/Statement/Question } & \multirow{2}{*}{$\begin{array}{l}\text { Quest- } \\
\text { ion } \\
\text { Style }\end{array}$} & \multicolumn{5}{|c|}{ Likert Responses } \\
\hline & & 瑥。 & 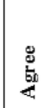 & 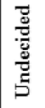 & 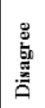 & 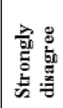 \\
\hline \multicolumn{7}{|l|}{ A. System Effectiveness } \\
\hline 1. I am now more aware of my affected arm & Likert & 5 & & & & \\
\hline 2. My arm feels weaker & Likert & & & & 2 & 3 \\
\hline 3. My arm feels tighter & Likert & & & 1 & 3 & 1 \\
\hline 4. I can reach out with my arm more easily & Likert & 3 & 2 & & & \\
\hline 5. I can now pick up objects & Likert & 1 & 3 & 1 & & \\
\hline $\begin{array}{l}\text { 6. Are you now able to do things that you } \\
\text { could not do before? (Yes/No. Please give } \\
\text { examples and provide as much information } \\
\text { as possible) }\end{array}$ & Open & \multicolumn{5}{|l|}{ All yes } \\
\hline $\begin{array}{l}\text { 7. Are you now able to do things better than } \\
\text { you could before? (Yes/No. Please give } \\
\text { examples and provide as much information } \\
\text { as possible) }\end{array}$ & Open & \multicolumn{5}{|l|}{ All yes } \\
\hline $\begin{array}{l}\text { 8. Can you now perform any two handed tasks } \\
\text { more easily? (Yes/No; Please give } \\
\text { examples and provide as much information } \\
\text { as possible) }\end{array}$ & Open & \multicolumn{5}{|l|}{ All yes } \\
\hline $\begin{array}{l}\text { CARER/SPOUSE/RELATIVE } \\
\text { Do you think that (participant name) is now able } \\
\text { to: } \\
\text { i. do things that he/she could not do } \\
\text { ii. dofore? } \\
\text { before? } \\
\text { (Yes/No. Please give examples and provide as } \\
\text { much information as possible) }\end{array}$ & Open & \multicolumn{5}{|c|}{ Not asked } \\
\hline \multicolumn{7}{|l|}{ B. System Usability } \\
\hline 9. I did not find the treatment enjoyable & Likert & & & & 1 & 4 \\
\hline 10. It was easy to understand what I had to do & Likert & 4 & 1 & & & \\
\hline $\begin{array}{l}\text { 11. It was difficult to put my arm in the arm } \\
\text { holder. } \\
\text { MS3 - couldn't do it on own, wasn't } \\
\text { difficult with Trish's help. }\end{array}$ & Likert & & 1 & & 3 & 1 \\
\hline 12. The arm holder was comfortable & Likert & 3 & 2 & & & \\
\hline 13. The stimulation was uncomfortable & Likert & & & 1 & 3 & 1 \\
\hline $\begin{array}{l}\text { 14. The target (i.e., the moving ball) was easy } \\
\text { to see } \\
\text { MS1 - due to visual problems - sometimes } \\
\text { difficulty to see - usually fine }\end{array}$ & Likert & 4 & & & 1 & \\
\hline $\begin{array}{l}\text { 15. The trajectory (i.e., length, height, } \\
\text { direction) was easy to see }\end{array}$ & Likert & 3 & 2 & & & \\
\hline $\begin{array}{l}\text { 16. I did not understand the graphs showing my } \\
\text { performance }\end{array}$ & Likert & & 1 & & 3 & 1 \\
\hline \multicolumn{7}{|l|}{$\begin{array}{l}\text { C. Questions about how the system could be } \\
\text { improved }\end{array}$} \\
\hline $\begin{array}{l}\text { 17. Adding games would add to my motivation } \\
\text { and enjoyment of the treatment }\end{array}$ & Likert & 2 & 1 & 1 & 1 & \\
\hline $\begin{array}{l}\text { 18. I would not like to have more arm muscles } \\
\text { stimulated }\end{array}$ & Likert & & & & 2 & 3 \\
\hline $\begin{array}{l}\text { 19. How do you think the task could be } \\
\text { improved? }\end{array}$ & Open & & & & & \\
\hline \multicolumn{7}{|l|}{ D. General Questions } \\
\hline $\begin{array}{l}\text { 20. I would not recommend the treatment to } \\
\text { other people who have had MS }\end{array}$ & Likert & & & & 1 & 4 \\
\hline $\begin{array}{l}\text { 21. I would have liked to have continued longer } \\
\text { with the treatment }\end{array}$ & Likert & 2 & 3 & & & \\
\hline $\begin{array}{l}\text { 22. Looking back on it, was taking part in this } \\
\text { study worthwhile for you? (Yes/No; please } \\
\text { provide as much information as possible) }\end{array}$ & Open & \multicolumn{5}{|l|}{ All yes } \\
\hline 23. What were the worst aspects of it? & Open & & & & & \\
\hline 24 . What were the best aspects of it? & Open & & & & & \\
\hline \multicolumn{7}{|l|}{ E. Dreamtime } \\
\hline $\begin{array}{l}\text { 25. If we could design the ideal rehabilitation } \\
\text { system describe five features it should } \\
\text { have: }\end{array}$ & Open & & & & & \\
\hline $\begin{array}{l}\text { 26. If we could stimulate more muscles which } \\
\text { movements would you like? }\end{array}$ & Open & & & & & \\
\hline
\end{tabular}




\section{ACKNOWLEDGMENT}

The authors would like to thank the people with MS who participated in this study. They would also like to thank S. K. Wee and E. Hallewell for conducting the clinical assessments.

\section{REFERENCES}

[1] F. Khan, L. Turner-Stokes, L. Ng, and T. Kilpatrick, "Multidisciplinary rehabilitation for adults with multiple sclerosis," Cochrane Database Syst. Rev., Tech. Rep. CD006036, 2007.

[2] A. I. Spooren, A. A. Timmermans, and H. A. Seelen, "Motor training programs of arm and hand in patients with MS according to different levels of the ICF: A systematic review," BMC Neurol, vol. 12, p. 49, 2012.

[3] S. Johansson, C. Ytterberg, I. Claesson, J. Lindberg, J. Hillert, M. Andersson, L. Widen Holmqvist, and L. Koch, "High concurrent presence of disability in multiple sclerosis," J. Neurol., vol. 254, pp. 767-773, 2007.

[4] U. Einarsson, K. Gottberg, S. Fredikson, L. Von Koch, and L. W. Holmqvist, "Activities of daily living and social activities in people with multiple sclerosis in Stockholm county," Clin. Rehabil., vol. 20, pp. 543-551, 2006.

[5] J. E. Deutsch, A. S. Merians, S. Adamovich, H. Poizner, and G. C. Burdea, "Development and application of virtual reality technology to improve hand use and gait of individuals post-stroke," Restor. Neurol. Neurosci., vol. 22, pp. 371-386, 2004.

[6] T. Paillard, F. Noe, P. Passelergue, and P. Dupui, "Electrical stimulation superimposed onto voluntary muscular contraction," Sports Med. vol. 35, pp. 951-966, 2005.

[7] M. Glanz, S. Klawansky, W. Stason, C. Berkley, and T. C. Chalmers, "Functional electrostimulation in poststroke rehabilitation: A meta-analysis of the randomized controlled trials," Arch. Phys. Med. Rehabil., vol. 77, pp. 549-553, 1996.

[8] J. Glinsky, L. Harvey, and P. Van Es, "Efficacy of electrical stimulation to increase muscle strength in people with neurological conditions: A systematic review," Physiother Res. Int., vol. 12, pp. 175-194, 2007.

[9] R. Martin, C. Sadowsky, K. Obst, B. Meyer, and J. Mcdonald, "Functional electrical stimulation in spinal cord injury: From theory to practice," Top Spinal Cord Inj. Rehabil., vol. 18, pp. 28-33, 2012.

[10] Y. J. Chang, M. J. Hsu, S. M. Chen, C. H. Lin, and A. M. Wong, "Decreased central fatigue in multiple sclerosis patients after 8 weeks of surface functional electrical stimulation," J. Rehabil. Res. Dev., vol. 48, pp. 555-564, 2011.

[11] J. E. Esnouf, P. N. Taylor, G. E. Mann, and C. L. Barrett, "Impact on activities of daily living using a functional electrical stimulation device to improve dropped foot in people with multiple sclerosis, measured by the canadian occupational performance measure," Mult. Scler., vol. 16, pp. 1141-1147, 2010

[12] L. Paul, D. Rafferty, S. Young, L. Miller, P. Mattison, and A. Mcfadyen, "The effect of functional electrical stimulation on the physiological cost of gait in people with multiple sclerosis," Mult. Scler., vol. 14, pp. 954-961, 2008.

[13] L. Hughes, A. Donnelly, G. Rainsford, and S. Coote, "Augmenting an exercise programme with electrical stimulation for people with multiple sclerosis-The effect on strength and fatigue," Physiotherapy, vol. 97, pp. S511-S512, 2011.

[14] T. Broekmans, M. Roelants, P. Feys, G. Alders, D. Gijbels, I. Hanssen, P. Stinissen, and B. O. Eijnde, "Effects of long-term resistance training and simultaneous electro-stimulation on muscle strength and functional mobility in multiple sclerosis," Mult. Scler., vol. 17, pp. 468-477, 2011.

[15] J. N. Ratchford, W. Shore, E. R. Hammond, J. G. Rose, R. Rifkin, P. Nie, K. Tan, M. E. Quigg, B. J. De Lateur, and D. A. Kerr, "A pilo study of functional electrical stimulation cycling in progressive multiple sclerosis," NeuroRehabil., vol. 27, pp. 121-128, 2010.

[16] G. Kwakkel, B. J. Kollen, and H. I. Krebs, "Effects of robot-assisted therapy on upper limb recovery after stroke: A systematic review," Neurorehab. Neural Repair, vol. 22, pp. 111-121, 2008.

[17] J. Mehrholz, A. Hadrich, T. Platz, J. Kugler, and M. Pohl, "Electromechanical and robot-assisted arm training for improving generic activities of daily living, arm function, and arm muscle strength after stroke," Cochrane Database Syst. Rev., vol. 6, p. CD006876, 2012.

[18] D. Gijbels, I. Lamers, L. Kerkhofs, G. Alders, E. Knippenberg, and P. Feys, "The armeo spring as training tool to improve upper limb functionality in multiple sclerosis: A pilot study," J. Neuroeng. Rehabil., vol. 8, pp. 5-5, 2011.
[19] E. Vergaro, V. Squeri, G. Brichetto, M. Casadio, P. Morasso, C. Solaro, and V. Sanguineti, "Adaptive robot training for the treatment of incoordination in multiple sclerosis," J. Neuroeng. Rehabil., vol. 7, pp. 37-37, 2010.

[20] I. Carpinella, D. Cattaneo, S. Abuarqub, and M. Ferrarin, "Robot-based rehabilitation of the upper limbs in multiple sclerosis: Feasibility and preliminary results," J. Rehabil. Med. (Stiftelsen Rehabiliteringsinformation), vol. 41, pp. 966-970, 2009.

[21] M. Casadio, V. Sanguineti, P. Morasso, and C. Solaro, "Abnormal sensorimotor control, but intact force field adaptation, in multiple sclerosis subjects with no clinical disability," Mult. Scler., vol. 14, pp. 330-342, 2008.

[22] V. Squeri, E. Vergaro, G. Brichetto, M. Casadio, P. G. Morasso, C. Solaro, and V. Sanguinetti, "Adaptive robot training in the rehabilitation of incoordination in multiple sclerosis: A pilot study," in Proc. IEEE 10th Int. Conf. Rehabil. Robot., 2007, pp. 364-370.

[23] I. Carpinella, D. Cattaneo, R. Bertoni, and M. Ferrarin, "Robot training of upper limb in multiple sclerosis: Comparing protocols with or without manipulative task components," IEEE Trans Neural Syst. Rehabil. Eng., vol. 20, no. 3, pp. 351-360, 2012.

[24] A. M. Hughes, C. T. Freeman, J. H. Burridge, P. H. Chappell, P. L. Lewin, and E. Rogers, "Feasibility of iterative learning control mediated by functional electrical stimulation for reaching after stroke," $J$. Neurorehabil. Neural Repair, vol. 23, pp. 559-568, 2009.

[25] K. L. Meadmore, A. M. Hughes, C. T. Freeman, J. H. Burridge, D. Tong, Z. Cai, and E. Rogers, " $<$ PLEASE PROVIDE PAGE NUMBERS.> Functional electrical stimulation mediated by iterative learning control and $3 \mathrm{D}$ robotics reduces motor impairment in chronic stroke," J. Neuroeng. Rehabil., vol. 32, no. 9, 2012.

[26] C. T. Freeman, "Upper limb electrical stimulation using input-output linearization and iterative learning control," IEEE Trans. Control Syst. Technol. [Online]. Available: http://dx.doi.org/10.1109/TCST.2014. 2363412

[27] C. T. Freeman and Y. Tan, "Iterative learning control with mixed constraints for point-to-point tracking," IEEE Trans. Control Syst. Technol., vol. 21, no. 3, pp. 604-616, May 2013.

[28] C. T. Freeman, T. Exell, K. L. Meadmore, E. Hallewell, and A.-M. Hughes, "Computational models of upper limb motion during functional reaching tasks for application in FES based stroke rehabilitation," Biomed. Eng. J., 10.1515/bmt-2014-0011.

[29] D. H. Owens, C. T. Freeman, and B. Chu, "Multivariable norm optimal iterative learning control with auxiliary optimization," Int. J. Contol, vol. 86, no. 6, pp. 1026-1045, 2013.

[30] F. Le, I. Markovsky, C. T. Freeman, and E. Rogers, "Identification of electrically stimulated muscle models of stroke patients," Control Eng. Practice, vol. 18, pp. 396-407, 2010.

[31] C. T. Freeman, A. M. Hughes, J. H. Burridge, P. H. Chappell, P. L. Lewin, and E. Rogers, "A model of the upper extremity using surface FES for stroke rehabilitation," ASME J. Biomech. Eng., vol. 131, no. 3, p. 031011, 2009.

[32] I. Lamers, A. A. Timmermans, L. Kerkhofs, D. Severijns, B. Van Wijmeersch, and P. Feys, "Self-reported use of the upper limbs related to clinical tests in persons with multiple sclerosis," Disabil. Rehabil., vol. 35, pp. 2016-2020, 2013

[33] N. Yozbatiran, L. Der-Yeghiaian, and S. C. Cramer, "A standardized approach to performing the action research arm test," Neurorehabil. Neural Repair, vol. 22, pp. 78-90, 2008.

[34] R. C. Lyle, "A performance test for assessment of upper limb function in physical rehabilitation treatment and research," Int. J. Rehabil. Res., vol. 4, pp. 483-492, 1981.

[35] I. Lamers, L. Kerkhofs, J. Raats, D. Kos, B. Van Wijmeersch, and P. Feys, "Perceived and actual arm performance in multiple sclerosis: Relationship with clinical tests according to hand dominance," Mult. Scler., vol. 19, pp. 1341-1348, 2013.

[36] V. Mathiowetz, K. Weber, N. Kashman, and G. Volland, "Adult norms for the nine hole peg test of finger dexterity," Occupational Therapy J. Res., vol. 5, pp. 24-38, 1985.

[37] D. E. Goodkin, D. Hertsgaard, and J. Seminary, " $<$ PLEASE PROVIDE YEAR.> Upper extremity function in multiple sclerosis: Improving assessment sensitivity with box-and-block and nine-hole peg tests," Arch. Phys. Med. Rehabil., vol. 69, pp. 850-854.

[38] B. Kopp, A. Kunkel, H. Flor, T. Platz, U. Rose, K. H. Mauritz, K. Gresser, K. L. Mcculloch, and E. Taub, "The arm motor ability test: Reliability, validity, and sensitivity to change of an instrument for assessing disabilities in activities of daily living," Arch. Phys. Med. Rehabil., vol. 78, pp. 615-620, 1997. 
[39] C. C. Chen and R. K. Bode, "Psychometric validation of the manual ability measure-36 (MAM-36) in patients with neurologic and musculoskeletal disorders," Arch. Phys. Med. Rehabil., vol. 91, pp. 414-420, 2010.

[40] A. R. Fugl-Meyer, L. Jaasko, I. Leyman, S. Olsson, and S. Steglind, "The post-stroke hemiplegic patient. 1. A method for evaluation of physical performance," Scand. J. Rehabil. Med., vol. 7, pp. 13-31, 1975.

[41] P. W. Duncan, M. Propst, and S. G. Nelson, "Reliability of the FuglMeyer assessment of sensorimotor recovery following cerebrovascular accident," Phys. Ther., vol. 63, pp. 1606-1610, 1983.

[42] D. J. Gladstone, C. J. Danells, and S. E. Black, "The Fugl-Meyer assessment of motor recovery after stroke: A critical review of its measurement properties," Neurorehabil. Neural Repair, vol. 16, pp. 232-240, 2002.

[43] T. Platz, C. Pinkowski, F. van Wijck, I. H. Kim, P. di Bella, and G. Johnson, "Reliability and validity of arm function assessment with standardized guidelines for the Fugl-Meyer test, action research arm test and box and block test: A multicentre study," Clin. Rehabil., vol. 19, no. 4, pp. 404-411, Jun. 2005.

[44] H. Bastiaens, G. Alders, P. Feys, S. Notelaers, K. Coninx, L. Kerkhofs, V. Truyens, R. Geers, and A. Goedhart, " $<$ PLEASE PROVIDE PAGE NUMBERS OR LOCATION.> Facilitating robot-assisted training in MS patients with arm paresis: A procedure to individually determine gravity compensation," in Proc. 12th IEEE Int. Conf. Rehabil. Robot., 2011.

[45] C. H. Polman and R. A. Rudick, "The multiple sclerosis functional composite: A clinically meaningful measure of disability," Neurol., vol. 74, pp. S8-S15, 2010.

[46] S. Whitling, N. B. Lincoln, G. Bhavnani, and J. Cockburn, "Rivermead perceptual assessment battery," Occupational Therapy in Health Care, vol. 3, pp. 209-210, 1986.

[47] R. Turk, J. Burridge, D. Merrill, A.-M. Hughes, G. Cosendai, and J. Schulman, " $<$ PLEASE PROVIDE PAGE NUMBERS OR LOCATION.> Clinical effectiveness and participant perceptions of an implanted closed-loop neurostimulator-sensor system for arm rehabilitation post-stroke," in Proc. Int. Functional Elect. Stimulation Soc. Annu. Conf., 2008.

[48] K. L. Meadmore, A.-M. Hughes, C. T. Freeman, Z. Cai, D. Tong, J. H. Burridge, and E. Rogers, "<PLEASE PROVIDE PAGE NUMBERS.> Functional electrical stimulation mediated by iterative learning control and 3D robotics reduces motor impairment in chronic stroke," J. Neuroeng. Rehabil., vol. 9, no. 32, 2012.

[49] L. A. Pilutti, T. A. Greenlee, R. W. Motl, M. S. Nickrent, and S. J. Petruzzello, "Effects of exercise training on fatigue in multiple sclerosis: A meta-analysis," Psychosom. Med., vol. 75, no. 6, pp. 575-580, Jul.-Aug. 2013.
[50] S. Coote, L. Hughes, G. Rainsford, C. Minogue, and A. Donnelly, " $>$ PLEASE PROVIDE URL OR VOLUME AND PAGE NUMBERS.> A pilot randomized trial of progressive resistance exercise augmented by neuromuscular electrical stimulation for people with multiple sclerosis who use walking aids," Arch. Phys. Med. Rehabil., 2014.

[51] D. Severijns, I. Lamers, L. Kerkhofs, and P. Feys, “<PLEASE PROVIDE DOI NUMBER.> Hand grip fatigability in persons with multiple sclerosis according to hand dominance and disease progression," J. Rehabil. Med., Sep. 2014.

[52] C. Confavreux and S. Vukusic, "Natural history of multiple sclerosis: A unifying concept," Brain, vol. 129, pp. 606-616, 2006.

[53] A. Tallner, A. Waschbisch, I. Wenny, S. Schwab, C. Hentschke, K. Pfeifer, and M. Maurer, "Multiple sclerosis relapses are not associated with exercise," Mult. Scler., vol. 18, pp. 232-235, 2012.

\section{Patrica Sampson PLEASE PROVIDE BIOGRAPHICAL INFORMA- TION AND PHOTO IF AVAILABLE FOR ALL AUTHORS.}

Chris Freeman Please provide biographical information.

Susan Coote Please provide biographical information.

Sara Demain Please provide biographical information.

Peter Feys Please provide biographical information.

Katie Meadmore Please provide biographical information.

Ann-Marie Hughes Please provide biographical information. 


\title{
Using Functional Electrical Stimulation Mediated by Iterative Learning Control and Robotics to Improve Arm Movement for People With Multiple Sclerosis
}

\author{
Patrica Sampson, Chris Freeman, Susan Coote, Sara Demain, Peter Feys, Katie Meadmore, and \\ Ann-Marie Hughes
}

\begin{abstract}
Few interventions address multiple sclerosis (MS) arm dysfunction but robotics and functional electrical stimulation (FES) appear promising. This paper investigates the feasibility of combining FES with passive robotic support during virtual reality (VR) training tasks to improve upper limb function in people with multiple sclerosis (pwMS). The system assists patients in following a specified trajectory path, employing an advanced model-based paradigm termed iterative learning control (ILC) to adjust the FES to improve accuracy and maximise voluntary effort. Reaching tasks were repeated six times with ILC learning the optimum control action from previous attempts. A convenience sample of five pwMS was recruited from local MS societies, and the intervention comprised 18 one-hour training sessions over 10 weeks. The accuracy of tracking performance without FES and the amount of FES delivered during training were analyzed using regression analysis. Clinical functioning of the arm was documented before and after treatment with standard tests. Statistically significant results following training included: improved accuracy of tracking performance both when assisted and unassisted by FES; reduction in maximum amount of FES needed to assist tracking; and less impairment in the proximal arm that was trained. The system was well tolerated by all participants with no increase in muscle fatigue reported. This study confirms the feasibility of FES combined with passive robot assistance as a potentially effective intervention to improve arm movement and control in pwMS and provides the basis for a follow-up study.
\end{abstract}

Index Terms-Functional electrical stimulation (FES), iterative learning control (ILC), Multiple Sclerosis (MS), rehabilitation, robot-therapy, upper limb, virtual reality (VR).

Manuscript received May 09, 2014; revised November 05, 2014 and January 29, 2015; accepted March 13, 2015. Date of publication March 24, 2015; date of current version nulldate. This work was supported by the Multiple Sclerosis Society in the U.K. under Grant 973/12.

P. Sampson, S. Demain, and A.-M. Hughes are with the Rehabilitation and Health Technologies Research Group, Faculty of Health Sciences, University of Southampton, U.K. (e-mail: P.Sampson@soton.ac.uk; S.H.Demain@soton. ac.uk; A.Hughes@soton.ac.uk).

C. Freeman and K. Meadmore are with Faculty of Physical Sciences and Engineering; University of Southampton, Southampton SO17 1BJ, U.K. (e-mail: cf@ecs.soton.ac.uk; klm301@soton.ac.uk).

S. Coote is with the Clinical Therapies Department, University of Limerick, Castletroy, Co., Limerick, Ireland (e-mail: Susan.Coote@ul.ie).

P. Feys is with REVAL/BIOMED Research Institute, Hasselt University, 3900 Diepenbeek, Belgium (e-mail: peter.feys@uhasselt.be).

Color versions of one or more of the figures in this paper are available online at http://ieeexplore.ieee.org.

Digital Object Identifier 10.1109/TNSRE.2015.2413906

\section{INTRODUCTION}

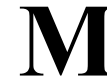
ULTIPLE SCLEROSIS (MS) is a chronic, degenerative, autoimmune disorder, which affects the central nervous system leading to a wide range of symptoms including upper limb weakness. Despite advances in pharmaceutical options to reduce the number and severity of relapses, rehabilitation continues to play an essential role in reducing motor disability in people with MS (pwMS) [1]. However, studies relating to rehabilitation of the upper limb in MS remain limited [2] despite the high percentage of pwMS who have upper limb symptoms, classified within the impairments and activity domains of the International Classification of Functioning Disability and Health (ICF). Using the nine hole peg test (9HPT) $76 \%$ of 219 pwMS were identified to have reduced manual dexterity [3] and $50 \%(n=219)$ and $67 \%(n=166)$ of pwMS experience limitations in activities of daily living (ADL) and social activities, respectively, [3], [4]. Arm and hand use is important to enable independence in everyday life, however effective treatment strategies for the impaired upper limb are not currently available. In degenerative neurological conditions such as MS the aim of rehabilitation is on improving or maintaining a person's current function and independence for as long as possible. PwMS most often only show arm dysfunction at later stages of the disease, when the MS disease course has become progressive instead of relapsing-remitting. However, progression can be slow, so benefits obtained from focused interventions can lead to functional improvements lasting from months to years. The purpose of the intervention is not muscle strengthening per se, but improving motor coordination of multiple limb segments, with focus on the quality of the executed movement. In that sense, the approach is impairment based as well as different to, for example, constrained induced movement therapy, which allows compensatory movements during functional activities. FES is however applicable in severely disabled upper limbs, and is thought to provide a neural sound basis for further functional rehabilitation. New strategies to achieve this rehabilitation aim need to be developed and evaluated.

The essential component of sensory-motor training in both healthy and impaired people is intensive practice in an environment that provides varied challenging tasks, success and sensory-motor feedback of performance that enhance motivation and attention [5]. Functional electrical stimulation (FES) and 


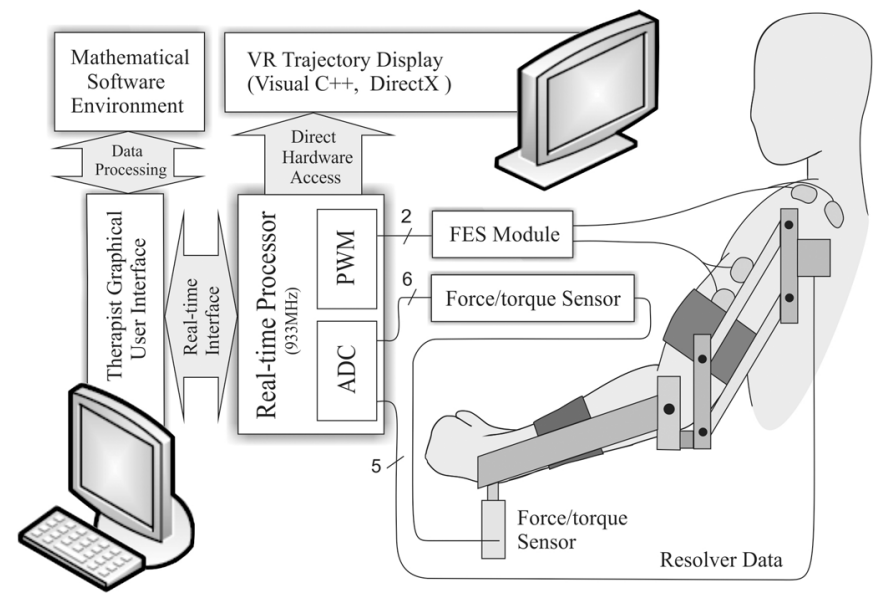

Fig. 1. Signal flow diagram showing system components: passive robot; realtime processor; FES hardware; therapist and participant displays.

passive or active robotic systems are ideally placed to deliver these type of interventions.

FES has been shown to be effective in augmenting strength in healthy people [6], stroke [7], [8] and spinal cord injury [9] and in reducing motor fatigue in MS [10]. In MS, the orthotic effect of FES is well documented as an effective treatment for foot drop [11], [12]. A further three studies involving the lower limb have evaluated the therapeutic effect of FES on strength for pwMS. For example, Hughes et al. [13] showed electrical stimulation augmented a strengthening programme for pwMS who used walking aids. Broekmans et al. [14] compared the effect of adding electrical stimulation to a 20 week progressive resistance training in a mildly disabled population of pwMS. Both interventions showed small improvements in strength but these did not translate to change on functional measures. Modest increases have also been reported in strength, significant improvements in walking tests $(p<0.05)$, and in perceived physical health [15]. Despite this evidence for the effectiveness of FES for the lower limb, to date, no studies have evaluated the effectiveness of FES for the upper extremity. Furthermore, existing studies have employed open-loop control of FES for MS rehabilitation, which do not maximize accuracy or promote voluntray effort, hence limiting the effectiveness of therapy.

Systematic reviews have concluded that robots or electromechanical devices have a beneficial effect on arm impairment and generic ADLs post stroke [16], [17]. In MS, several pilot studies have demonstrated positive effects of robotic training on reducing upper limb impairment and some improvement at the activity level [18]-[23].

This paper examines the feasibility of combining FES and passive robotic support for MS rehabilitation. An advanced control approach termed iterative learning control (ILC) is used to finely adjust the assistance provided to precisely correct performance error in the next attempt of a specific task. ILC uses a biomechanical model of the arm and support system to encourage and support participants' voluntary effort by supplying just enough FES to achieve the movement. ILC is one of the few advanced control approaches to have been successfully applied to reduce upper limb impairments due to chronic stroke, with results showing that combining FES and robotics to enable precise

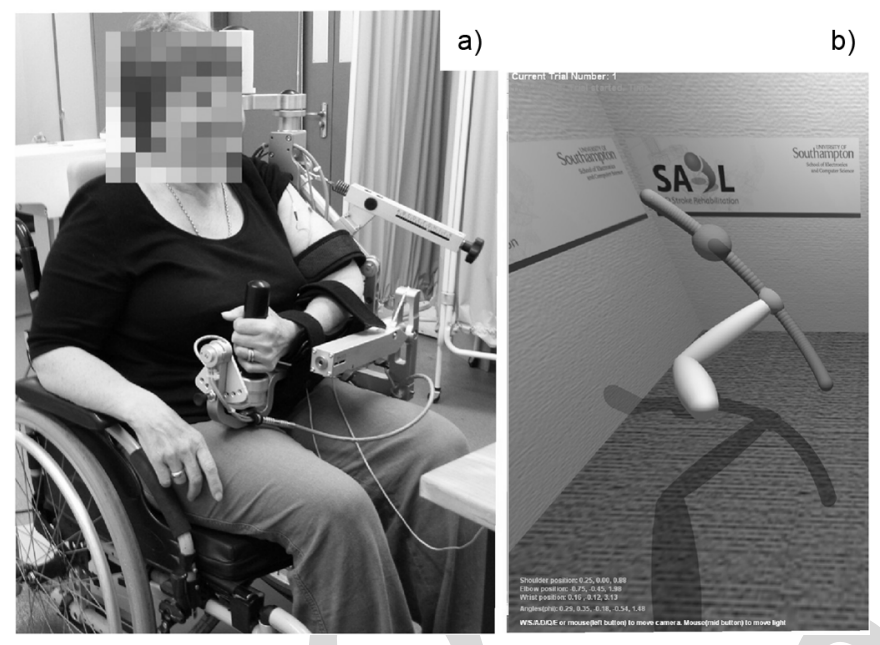

Fig. 2. a) Participant using mechanical support with FES applied using electrodes to her left triceps and anterior deltoid muscles; b) a monitor shows the trajectory task (blue) that the participant needs to follow with their arm (white) with a ball (orange) indicating they are on target for this reaching movement.

assistance of both planar [24] and 3-D upper arm tasks [25] led to improved accuracy in participants' reaching movements. The current system is a further refinement of this technology, embedding new developments in the underlying models and ILC algorithms [26], [27] that enable the tasks to be completed in a manner that more closely matches unimpaired motion. Termed SAIL: Stimulation Assisted by Iterative Learning, it includes a virtual reality (VR) environment depicting a reaching movement on a computer monitor. FES is applied to the triceps and anterior deltoid whilst the arm is supported in a passive robot. The aim of this study is to investigate the feasibility of using the SAIL system to improve arm movement and control for pwMS. This may be due to improving motor control through neuroplastic changes or local muscular changes.

\section{Methods}

\section{A. System Description and Set-Up}

The SAIL system comprises an instrumented passive robotic support, providing kinematic data to a realtime processor that interfaces with custom FES hardware, a VR task display, and a graphical user interface. These elements are shown schematically in Fig. 1 and are described in the following subsections. The participant's screen (located on their hemiplegic side) shows the trajectory to be tracked and a representation of the participant's arm (which mirrors the participant's movements in real-time). The support and trajectory task are depicted in Fig. 2. The display provides the participant with immediate visual feedback and facilitates motivation for the tracking task. The second screen displays a custom graphical user interface which is used by the therapist to select the tasks and adjust the parameters used by the FES control system.

1) Electrical Stimulation: FES electrodes are placed on the anterior deltoid and the triceps muscles. These are connected to a commercially available multi-channel FES device which has been adapted to receive inputs from the real-time control system. The frequency of stimulation is fixed at $40 \mathrm{~Hz}$, with a pulsewidth controlled in real-time by the ILC algorithms. To 


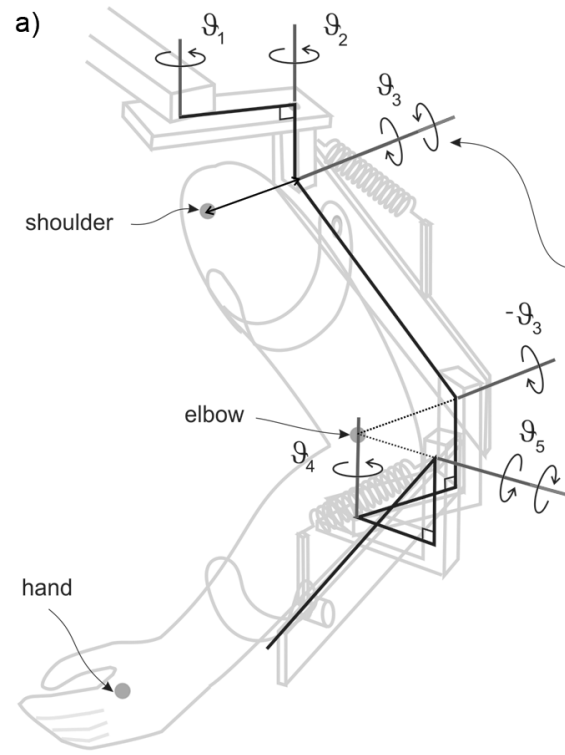

b)

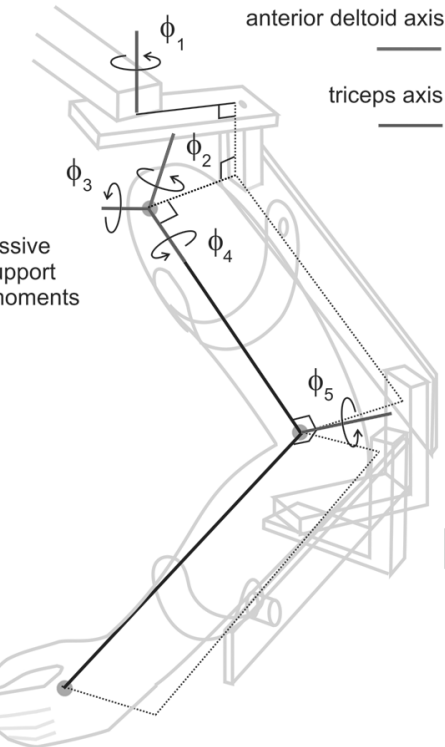

Fig. 3. Kinematic relationships and associated joint angles: a) mechanical support and b) human arm.

identify FES amplitudes for both muscles, the pulsewidth is set at a maximum value and the participant gradually increases the FES amplitude applied to each muscle until they reach a comfortable level that produces movement. Note that although the participant controls the FES amplitude, this is monitored by the therapist. The pulsewidth is then reduced to zero, and the stimulation amplitudes are then fixed for the remainder of each session to ensure participant comfort and safety.

2) Passive Robotic Support: A passive exoskeleton "un-weighing" system supports the participant's arm, providing an adjustable force against gravity via two springs incorporated into the mechanism. Each joint is aligned in either the horizontal or vertical plane, as shown in Fig. 3(a) which also describes the kinematic structure in terms of the measured joint variables, denoted $\boldsymbol{\Theta}=\left[\theta_{1}, \theta_{2}, \theta_{3}, \theta_{4}, \theta_{5}\right]^{\top}$. The participant's hemiplegic arm is loosely strapped into the support mechanism, which is adjusted so that their arm is fully supported off the knee.

3) Biomechanical Model: To promote effectiveness, assistance must precisely coincide with voluntary intention while simultaneously maximizing participant's effort. However, this has not been achieved in MS rehabilitation since existing FES controllers are open-loop. ILC addresses this problem in an optimal framework using a dynamic model of the stimulated arm, and is one of very few model-based upper limb FES control methodologies that has previously been used in upper limb stroke rehabilitation [24], [25]. ILC learns from past experience over repeated attempts of a tracking task in order to embed robustness to disturbance and model uncertainty.

The first stage in constructing a model is to map $\boldsymbol{\Theta}(t)$ to anthropomorphic joint angles. To achieve computationally tractable controllers it was assumed that anterior deltoid contraction produced movement about an axis that is fixed with respect to the trunk. This axis was identified by stimulating the muscle and then fitting a plane to the resulting movement of the elbow in 3-D space using least squares optimization [26] (Fig. 4 shows an example of this axis, which is normal to the

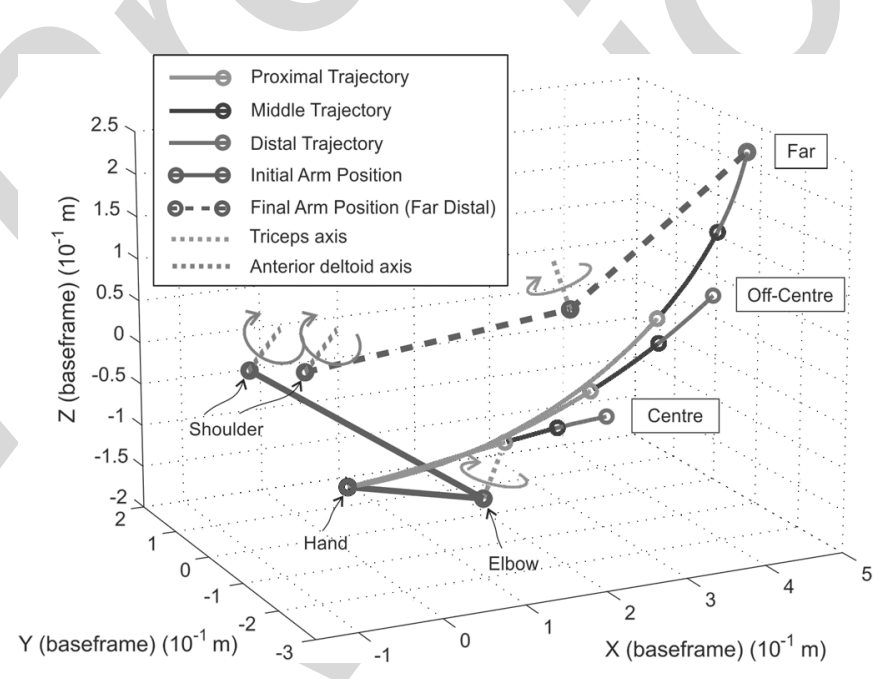

Fig. 4. Location of the arm, axis, and the nine possible trajectories for a participant: made up of direction (center, off center, far) and distance (proximal, middle, and distal). Each task lasted 8-13 s.

fitted plane). The anthropomorphically motivated variables are given by $\boldsymbol{\Phi}=\left[\phi_{1}, \phi_{2}, \phi_{3}, \phi_{4}, \phi_{5}\right]^{\top}$, and are shown in Fig. 3(b). A bijective transformation between coordinate sets is then constructed as $\boldsymbol{\Theta}=f(\boldsymbol{\Phi})$ enabling the combined model of the mechanical support and the human arm to be written as

$$
\boldsymbol{B}(\boldsymbol{\Phi}) \ddot{\boldsymbol{\Phi}}+\boldsymbol{C}(\boldsymbol{\Phi}, \dot{\boldsymbol{\Phi}}) \dot{\boldsymbol{\Phi}}+\boldsymbol{F}(\boldsymbol{\Phi}, \dot{\boldsymbol{\Phi}})+\boldsymbol{K}(\boldsymbol{\Phi})=\boldsymbol{\tau}(\boldsymbol{u}, \boldsymbol{\Phi}, \dot{\boldsymbol{\Phi}})-\boldsymbol{J}(\boldsymbol{\Phi})^{\top} \boldsymbol{h}
$$

where $\boldsymbol{B}(\cdot)$ and $\boldsymbol{C}(\cdot)$ are 5-by-5 inertial and Coriolis matrices, and the non-conservative matrix $\boldsymbol{F}(\cdot)$ accounts for joint stiffness, spasticity, gravity and the unweighing action of the robot. Vector $\boldsymbol{K}(\cdot)$ comprises moments produced through gravity compensation provided by each spring, $\boldsymbol{h}$ is the vector of externally applied force/torque (used only during model identification), and $\boldsymbol{\tau}(\boldsymbol{u}(t), \boldsymbol{\Phi}(t), \dot{\boldsymbol{\Phi}}(t))$ comprises moments generated by the vector, $\boldsymbol{u}(t)$, of stimulation pulsewidths (in microseconds, $\mu \mathrm{s}$ ) applied to each muscle. 


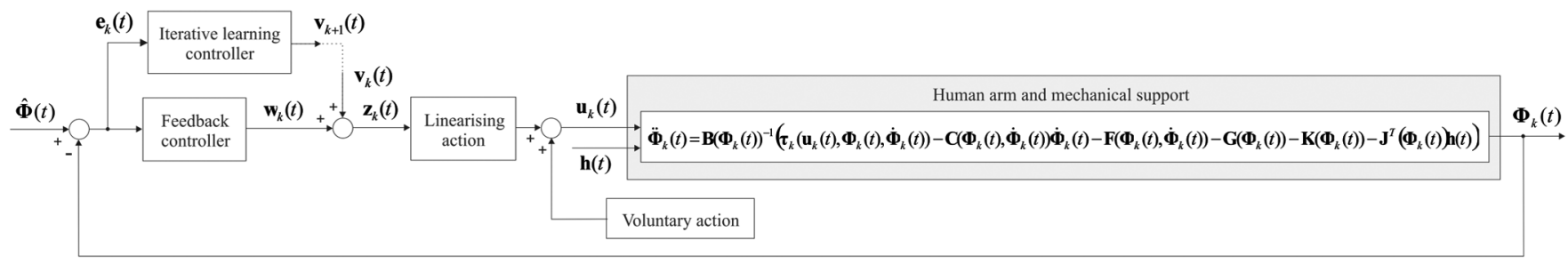

Fig. 5. Combined iterative learning and linearizing feedback FES control scheme showing model of the combined human arm and mechanical support.

4) Workspace and Trajectories: A workspace in which participants can extend to their full range of movement with assistance from FES is established by calculating the spatial coordinates from the highest point in ipsilateral space that the participant can reach when FES is applied to both muscle groups, the lowest point closest to the participant's contralateral thigh, and a front point relating to elbow extension directly in front of the participant. In this way, the workspace corresponds directly to the amount of movement produced by the FES. The reaching tasks comprise nine reaching movements, made up from three different directions and three different distances (see Fig. 4). These are scaled to fit within the workspace so that participants practice reaching within their safe range and exercise tolerance. To ensure each movement closely approximates unimpaired motion, the trajectories are individually customized for each participant using kinematic data collected from 14 unimpaired adults [28]. Reference trajectories for each joint are then extracted, and denoted by $\boldsymbol{\Phi}^{*}(t)$.

5) Control System: The control scheme is shown in Fig. 5 and contains an input-output linearizing feedback controller, together with a feedforward ILC update. The linearizing controller decouples the joints controlled by FES, to produce the form $\boldsymbol{z}_{k}=\left[\boldsymbol{\Phi}_{k, 2}^{(4)}, \boldsymbol{\Phi}_{k, 5}^{(4)}\right]^{\top}$. Here $x^{(i)}$ denotes the $i$ th time derivative of $x, k$ is the trial index, and the additional subscript denotes the component of the vector. Denoting $\boldsymbol{e}_{k}(t)=\boldsymbol{\Phi}^{*}(t)-\boldsymbol{\Phi}_{k}(t)$ as the error joint vector, a standard linear feedback controller with components $\boldsymbol{w}_{k, i}=C_{i}(s) \boldsymbol{e}_{k, i}$, $i \in\{2,5\}$ is then designed such that the roots of $s^{4}+C_{i}(s)=0$ lie in the left half of the $s$-plane. This guarantees stability of the stimulated joint angle dynamics, given by

$$
\begin{gathered}
{\left[\begin{array}{c}
\boldsymbol{e}_{k, 2} \\
\boldsymbol{e}_{k, 5}
\end{array}\right]=\left[\begin{array}{cc}
\frac{s^{4}}{\left(s^{4}+C_{2}(s)\right)} & 0 \\
0 & \frac{s^{4}}{\left(s^{4}+C_{5}(s)\right)}
\end{array}\right]\left[\begin{array}{l}
\hat{\phi}_{2} \\
\hat{\phi}_{5}
\end{array}\right]} \\
-\underbrace{\left[\begin{array}{cc}
\frac{1}{\left(s^{4}+C_{2}(s)\right)} & 0 \\
0 & \frac{1}{\left(s^{4}+C_{5}(s)\right)}
\end{array}\right]}_{G(s)}\left[\begin{array}{l}
\boldsymbol{v}_{k, 1} \\
\boldsymbol{v}_{k, 2}
\end{array}\right] .
\end{gathered}
$$

Note that this also guarantees stability of the joints $\phi_{1}, \phi_{3}, \phi_{4}$ that are not controlled through application of FES, as proven in [26]. Feedback action alone is not sufficient to achieve precise tracking of the reference trajectories. Therefore ILC is employed to update the feedforward signal $\boldsymbol{z}_{k}(t)$ between each attempt at the task, in order to drive FES-assisted components of the tracking error $\boldsymbol{e}_{k}(t)$ to zero. In choosing the stimulation supplied on trial $k+1$, ILC uses the stable, linear, decoupled system (2) to minimize a quadratic objective function of form

$$
\begin{aligned}
J\left(\boldsymbol{u}_{k+1}\right)=\int_{t=0}^{T}\left\{\left(\boldsymbol{v}_{k+1}(t)-\boldsymbol{v}_{k}(t)\right)^{\top} Q\left(\boldsymbol{v}_{k+1}(t)-\boldsymbol{v}_{k}(t)\right)\right. \\
\left.+\left[\boldsymbol{e}_{2, k+1}(t), \boldsymbol{e}_{5, k+1}(t)\right] R\left[\begin{array}{l}
\boldsymbol{e}_{2, k+1}(t) \\
\boldsymbol{e}_{5, k+1}(t)
\end{array}\right]\right\} d t
\end{aligned}
$$

where $T$ is the duration of the task. Through selection of positive-definite weighting matrices $Q$ and $R$, this objective function allows the designer to balance accuracy of task completion with the amount of FES applied to assist the participant's movement. The cost function (3) is solved using the update algorithm

$$
\boldsymbol{v}_{k+1}=\boldsymbol{v}_{k}+G^{*}(s)\left(I+G(0073) G^{*}(s)\right)^{-1}\left[\begin{array}{l}
\boldsymbol{e}_{k, 2} \\
\boldsymbol{e}_{k, 5}
\end{array}\right]
$$

where $G^{*}(s)$ is the adjoint of operator $G(s)$. Full details of the algorithm implementation, together with theoretical robustness and convergence properties, are given in [26] and [29].

6) Model Identification: The participant's upper arm and forearm lengths are measured and combined with the joint axis description of Section II-A3 to supply the kinematic relationship between the arm position in Cartesian space and the vector of joint angles, $\boldsymbol{\Phi}(t)$, as well as the system Jacobian matrix, $\boldsymbol{J}(\boldsymbol{\Phi})$. Next a six-axis sensor is attached to the extreme link of the robotic support and is held stationary while FES is applied to each muscle in turn. The resulting force $\boldsymbol{h}(t)$ recorded by the sensor is then related to the torque vector developed by the muscles $\boldsymbol{\tau}(\cdot)$ via the Jacobian matrix. A Hammerstein structure comprising a static isometric recruitment curve combined with linear activation dynamics is employed to model the response of each muscle to applied FES. This provides the dynamic relationship $\boldsymbol{\tau}(\boldsymbol{u}(t), \boldsymbol{\Phi}(t), \dot{\boldsymbol{\Phi}}(t))$, with details of the optimization procedure and validation of fitting accuracy given in [30]. Typical fitting results are shown in Fig. 6, where the stimulation applied to each muscle is a triangular ramp function. The terms $\boldsymbol{B}(\boldsymbol{\Phi}(t)), \boldsymbol{C}(\boldsymbol{\Phi}(t), \dot{\boldsymbol{\Phi}}(t))$, and $\boldsymbol{F}(\boldsymbol{\Phi}(t), \dot{\boldsymbol{\Phi}}(t))$ are all identified by applying FES to the muscles while moving the arm using the sensor, and using an optimization procedure on the resulting signals $\boldsymbol{h}(t)$ and $\boldsymbol{u}(t)$. In model validation experiments, the model has been found to fit experimental joint angle data sets with an accuracy which typically exceeds $90 \%$. Full details of the procedure used, as well as detailed fitting results, are given in [26] and [31]. Due to time constraints $\boldsymbol{B}(\cdot), \boldsymbol{C}(\cdot)$, and $\boldsymbol{F}(\cdot)$ were identified in a pilot session and then used throughout the intervention. 


\section{B. Clinical Test Design}

A proof-of-concept study with pwMS was undertaken to determine the effect on upper limb function of 18 one-hour sessions using the SAIL system to perform tracking tasks. All participants attended one pilot, two assessment, and eighteen intervention sessions at the University of Southampton, Faculty of Health Science (FoHS). The intervention was carried out by an experienced physiotherapy researcher. Two independent physiotherapists, unblinded to the intervention, performed the clinical assessments; the same physiotherapist performed both the pre and post assessment per participant. A semi-structured interview of participants' experience of using the SAIL system was completed by a health psychologist after the final assessment.

\section{Participants}

Following ethical approval (FoHS ETHICS-2013-5429) and written informed consent, a convenience sample of five pwMS was recruited from local MS society organizations around Southampton. Inclusion Criteria were: 1) confirmed diagnosis of MS; 2) impaired upper limb such that they were unable to achieve or maintain their arm at $90^{\circ}$ shoulder flexion, predominantly due to weakness; 3) FES produced movement without undue discomfort whilst the pwMS was seated with their arm in the robot; 4) could communicate effectively; 5) able to give informed consent. Exclusion Criteria were: 1) current relapse or commencement of steroids within 28 days of assessment; 2) marked intention tremor; 3) marked spasticity with Modified Ashworth $>2$ in shoulder flexors; 4) absent sensation in electrode sites; 5) any active device implant; 6) any metal implant in upper limb; 7) uncontrollable epilepsy; 8) pregnancy; 9) any serious or unstable medical or psychological condition or cognitive impairment; 10) current participation in another upper limb physical rehabilitation study. FES is an internationally recognized treatment for foot-drop in pwMS and stroke although there are specific contra-indications or risks when using FES; these formed part of our exclusion criteria. Recruitment occurred between June and September 2013. All participants completed the study and complied with the protocol.

\section{Intervention Sessions}

Each participant identified their most impaired arm. This was confirmed by the ARAT and FMA results, and was the arm treated. FES was applied as described in Section II-A, and the participant's arm was placed into the support mechanism. The level of arm support was personalized to ensure each person achieved their optimal range of movement. A pilot session was undertaken to identify the model and tune parameters in the ILC algorithms, a process lasting about $5 \mathrm{~min}$. The 18 intervention sessions then followed, during each of which the workspace was identified and the participant then practiced a minimum of six trajectories, each repeated six times, with a rest period of 2-10 s between each attempt. This provided between 18-33 min of treatment time. Participants were verbally encouraged during the reaching practice. The number of trajectories practiced increased during the intervention period to between eight and eleven according to participants' progress, fatigue, and motivation. Similarly, as participants progressed through the intervention, the level of support from the passive robot was gradually decreased according to their exercise tolerance. To assess unassisted performance, at the beginning and end of every session each participant tracked the same four different trajectories only once, with no FES.

\section{E. Outcome Measures}

The focus of this study was on the feasibility of the SAIL and whether pwMS could tolerate it. The primary outcome measures were change in amount of FES delivered and accuracy of task tracking over the treatment period. Secondary outcome measures evaluated clinical changes to the upper limb according to the impairment and activity domain of the ICF and were measured before treatment and within one week after the treatment period. The clinical outcome measures were: Action Research Arm Test (ARAT) [32]-[35]; Nine Hole Peg Test (9HPT) [35]-[37]; Manual Ability Measure (MAM-36) [38], [39]; and Fugl-Meyer Assessment (FMA) [35], [40]-[42]. The FMA, valid and reliable for assessing arm impairment in pwMS [43] and used to assess arm movement in pwMS [35], [44], measures motor control mainly at impairment level whereas the ARAT measures upper limb function using standardised activities. The MAM-36 is a valid measure of a person's perceived ability to use his/her hands and is meaningful to participants [39]. The MAM-36 raw score was converted to the MAM-36 measure using the conversion table [39]. The 9HPT is sensitive in assessing upper limb functional status change in pwMS [35], [37] and is part of MS composite score [45] where the task is to be completed within $300 \mathrm{~s}$. The Rivermead Perception Assessment Battery (RPAB) figure ground, 3-D copying and cancellation tests were used to assess 2-D, 3-D, and neglect, respectively [46], so that participants could be adequately supported during the intervention as the VR environment required visual perception.

A structured interview using a 26 item questionnaire based on one used in people with stroke [47] occurred immediately after the post-intervention assessment or later by telephone. Both open and closed questions were included to obtain an understanding of the system's effectiveness and usability; improvements required; and general questions about the intervention. Some of the open questions encouraged yes/no replies followed by an explanation: the remainder of the questions were completely open. Closed questions required a Likert-response indicating the extent of agreement (see Appendix A). The interview was purposely kept short, taking approximately $30 \mathrm{~min}$, although participants were encouraged to elaborate as much as possible. A psychologist who was not involved with delivering the intervention undertook the interview to encourage openness from participants.

\section{F. Statistical Analysis}

The clinical outcome measures: FMA; ARAT; MAM and 9HPT; measured at baseline and after the intervention, were analysed in SPSS v19 using the Wilcoxon signed-rank test. Conforming to prior studies [24], [48], the performance of tracking with FES (assisted) and without FES (unassisted) 

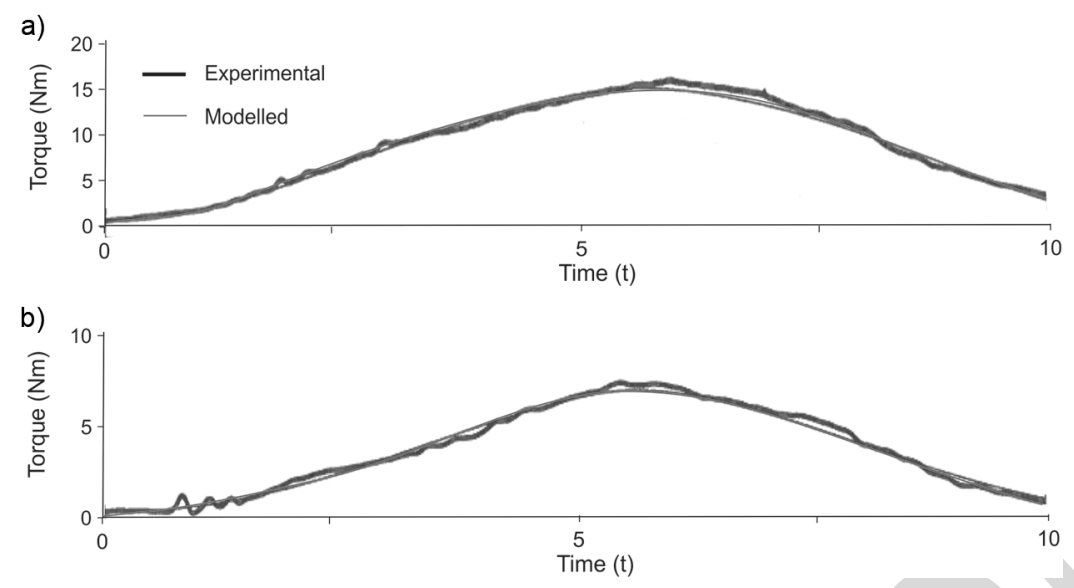

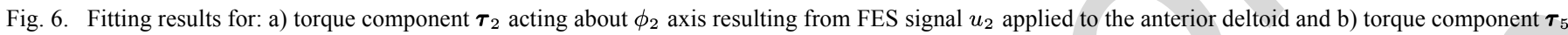
acting about $\phi_{5}$ axis resulting from FES signal $u_{5}$ applied to the triceps.

was analyzed per participant for each of the 18 sessions by calculating best-fit linear regression slopes of performance for each task. Two-tailed t-tests were applied, and the level of significance for all tests was set at $p<0.05$. The $95 \%$ confidence intervals were also calculated to provide a measure of how precisely the true mean can be bounded given the limited sample size. Tracking performance was calculated by taking the 2-norm of the error between arm position and target trajectory and normalizing it as follows: let $\boldsymbol{e}_{i, k}(t)$ denote the $i$ th element of vector $\boldsymbol{e}_{k}(t)$ at time " $t$ ", and similarly $\boldsymbol{\Phi}_{i}^{*}(t)$ the corresponding reference, then tracking performance of the $i$ th joint is given by

$$
100 \times\left(1-\sqrt{\frac{\int_{0}^{T} \boldsymbol{e}_{k, i}(t)^{2}}{\int_{0}^{T} \boldsymbol{\Phi}_{i}^{*}(t)^{2}}}\right) .
$$

A value of 100 indicated perfect tracking and 0 corresponded to no movement.

\section{G. Structured Interview}

Closed questions eliciting Likert responses were totalled and are presented in Appendix A.

\section{RESULTS}

Characteristic data for the five female participants who took part in the intervention are given in Table I. One participant with shoulder subluxation received additional supraspinatus FES to increase glenohumeral congruency and her reaching tasks were kept within a pain free range to avoid biomechanical impingement. All participants were able to increase the number of reaching tasks practised per session to between eight and eleven reaching tasks. All participants, except one, were able to receive less support from the passive robot during the reaching movements: the one participant's biceps tone increased on reducing the support so her support was kept constant. No serious adverse events were reported during the intervention period. One participant had 3-D visual impairment identified by the RPAB 3-D copying test $(4 / 24)$, and here the therapist
TABLE I

SOCIO-DEMOGRAPHIC CHARACTERISTICS OF PARTICIPANTS $(n=5)$

\begin{tabular}{lccccc}
\hline Pt Id & MS1 & MS2 & MS3 & MS4 & MS5 \\
\hline Age (years) & 60 & 40 & 61 & 51 & 61 \\
Type of MS & SPMS & RRMS & PPMS & SPMS & SPMS \\
Years MS diagnosed & 34 & 4 & 16 & 14 & 31 \\
Female/Male & $\mathrm{F}$ & $\mathrm{F}$ & $\mathrm{F}$ & $\mathrm{F}$ & $\mathrm{F}$ \\
Side treated & $\mathrm{L}$ & $\mathrm{R}$ & $\mathrm{L}$ & $\mathrm{L}$ & $\mathrm{R}$ \\
Original dominant hand & $\mathrm{R}$ & $\mathrm{R}$ & $\mathrm{R}$ & $\mathrm{R}$ & $\mathrm{R}$ \\
Full time wheelchair user & $\mathrm{Y}$ & $\mathrm{N}$ & $\mathrm{Y}$ & $\mathrm{Y}$ & $\mathrm{Y}$ \\
Glasses & $\mathrm{Y}$ & $\mathrm{N}$ & $\mathrm{Y}$ & $\mathrm{Y}$ & $\mathrm{Y}$ \\
\hline
\end{tabular}

Pt Id - participant identification, SPMS - secondary progressive MS, RRMS - relapse-remitting MS, PPMS - primary progressive MS, $\mathrm{F}$ - female, $\mathrm{M}$ - male, $\mathrm{L}$ - left, $\mathrm{R}$ - right, $\mathrm{Y}$ - yes, $\mathrm{N}$ - no.

assisted in directing the participant's arm movement during the tracking task. Her score of $12 / 24$ on the $3-\mathrm{D}$ copying test on completion of the intervention session suggests some 3-D learning may have occurred. All the other participants scored $\geq 18 / 24$ (normal perceptual range) [46] and were able to track independently. A future study should consider excluding 3-D visually impaired participants, ensuring the training is independent of the therapist.

\section{A. Assisted Tracking Performance}

Performance was calculated for the final attempt of every tracking task. These performances were then averaged to calculate the tracking performance and the maximum amount of FES provided. Data in Fig. 7(a) and (b) show improved accuracy of tracking performance at both the shoulder and elbow and Fig. 7(c) and (d) show the percentage maximum FES required to improve participants' tracking reduced over the treatment period. Table II shows the $p$-value and mean slope of the tracking performance and percentage maximum FES, which was statistically significant for each muscle group: triceps (elbow) and anterior deltoid (shoulder). The mean tracking performance slopes (elbow 0.71, shoulder 1.31) correspond to an average improvement over 18 sessions of $12.8 \%$ and $23.6 \%$ for the elbow and shoulder, respectively. The mean percentage maximum FES slopes (elbow -2.6805, shoulder -2.7143) correspond to an average reduction over 18 sessions of $49.2 \%$ and $48.8 \%$ for the elbow and shoulder, respectively. This suggests 
a)
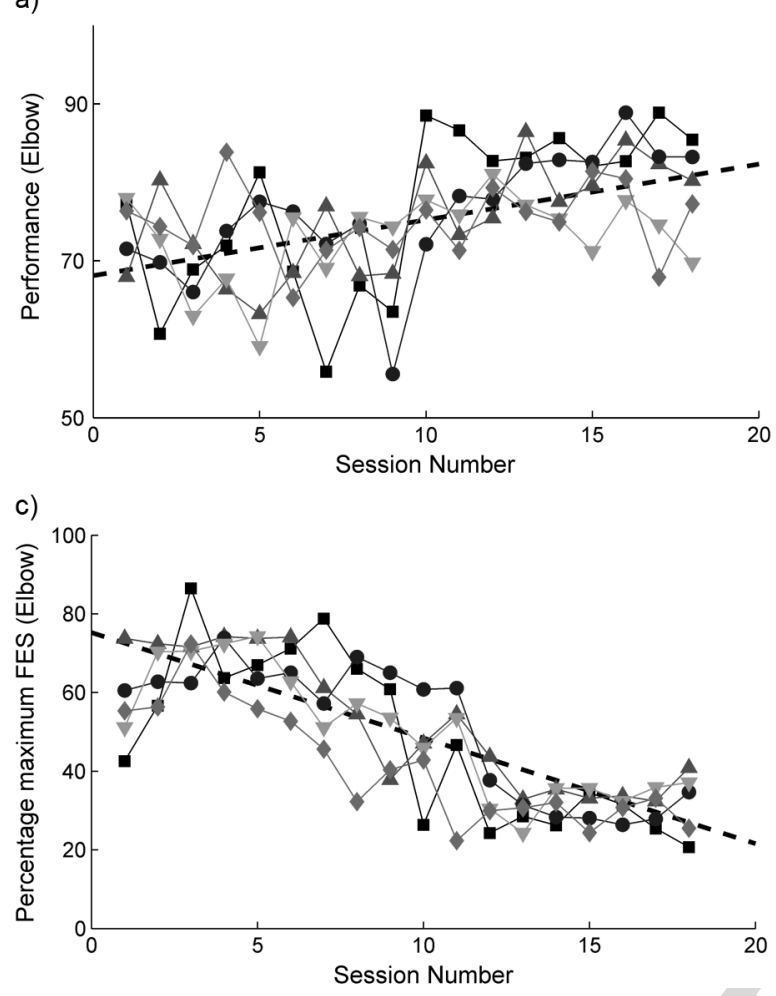

b)

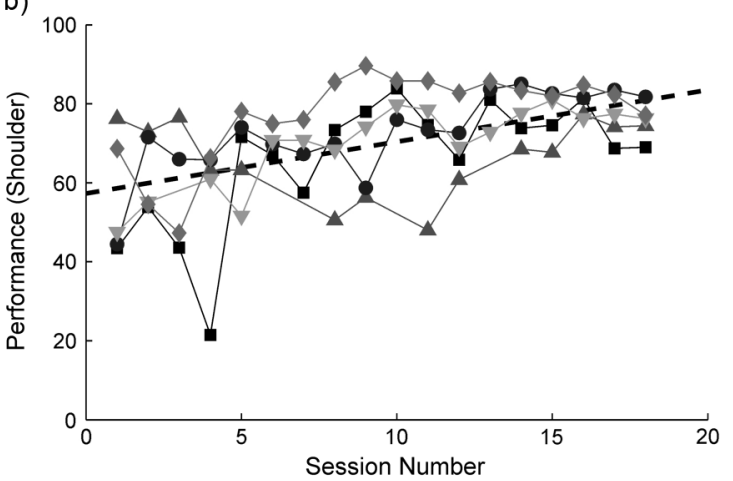

d)

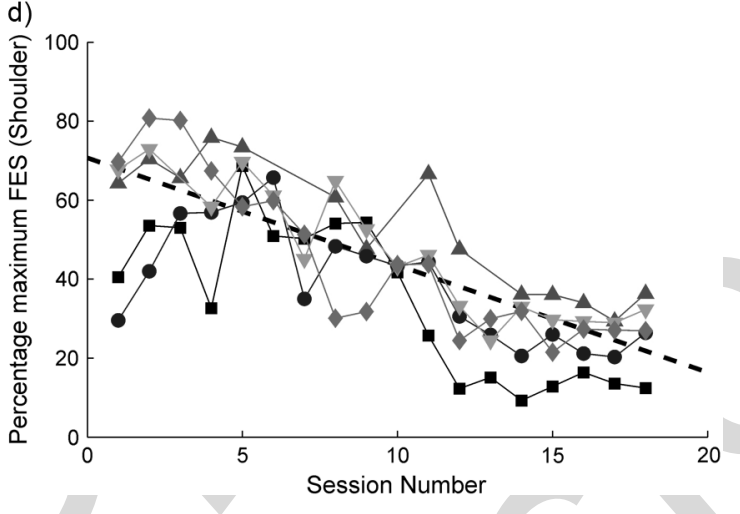

Fig. 7. Assisted task tracking accuracy and amount of FES, averaged over all tasks: a) accuracy of task tracking at the elbow; b) accuracy of task tracking at the shoulder; c) amount of FES applied at the elbow; and d) amount of FES applied at the shoulder. Mean of individual slopes shown by dotted line.

TABLE II

Tracking Performance Measures at the Elbow and Shoulder SHOWing THE MEAN SLOPE AND $p$-VALUe of THE BeSt Fit Linear REGRESSION LINES COLLAPSED ACROSS PARTICIPANTS FOR ASSISTED AND UNASSISTED TASKS

\begin{tabular}{|c|c|c|c|c|}
\hline \multirow[t]{2}{*}{ Task } & \multirow{2}{*}{$\begin{array}{l}\text { Elbow } \\
\text { Mean } \\
\text { slope }\end{array}$} & \multicolumn{3}{|c|}{ Shoulder } \\
\hline & & $\begin{array}{c}p \text {-value } \\
\text { CI }\end{array}$ & $\begin{array}{l}\text { Mean } \\
\text { slope }\end{array}$ & $\begin{array}{c}p \text {-value } \\
\text { CI }\end{array}$ \\
\hline \multicolumn{5}{|l|}{ Assisted } \\
\hline Tracking perf. $\%$ & 0.71 & $\begin{array}{c}0.027 \\
(0.13,1.28)\end{array}$ & 1.31 & $\begin{array}{c}0.015 \\
(0.42,2.20)\end{array}$ \\
\hline$\%$ maximum ES & -2.68 & $\begin{array}{c}0.000 \\
(-3.03,-2.33)\end{array}$ & -2.71 & $\begin{array}{c}0.000 \\
(-3.38,-2.04)\end{array}$ \\
\hline Tracking perf. $\% / \% \max$ ES & 0.12 & $\begin{array}{c}0.000 \\
(0.08,0.16)\end{array}$ & 0.19 & $\begin{array}{c}0.021 \\
(0.04,0.32)\end{array}$ \\
\hline \multicolumn{5}{|l|}{ Unassisted tracking perf. \% } \\
\hline Centre proximal & 2.37 & $\begin{array}{c}0.006 \\
(1.10,3.62)\end{array}$ & 6.24 & $\begin{array}{c}0.065 \\
(-0.62,13.10)\end{array}$ \\
\hline Centre distal & 1.91 & $\begin{array}{c}0.011 \\
(0.72,3.10)\end{array}$ & 6.31 & $\begin{array}{c}0.051 \\
(-0.08,12.69)\end{array}$ \\
\hline Off-centre middle $\% / \%$ max ES & 2.21 & $\begin{array}{c}0.018 \\
(0.61,3.81)\end{array}$ & 3.75 & $\begin{array}{c}0.017 \\
(1.09,6.40)\end{array}$ \\
\hline Far distal & 2.33 & $\begin{array}{c}0.006 \\
(1.08,3.58) \\
\end{array}$ & 3.33 & $\begin{array}{c}0.004 \\
(1.72,4.93) \\
\end{array}$ \\
\hline
\end{tabular}

Note: The small slope values are due to the different units in the axes. CI denotes $95 \%$ confidence interval.

that less FES was required to produce more accurate movement over the treatment period. This was confirmed when the slope of the tracking performance percentage was divided by the slope of the percentage maximum FES for each participant. Taking the mean over participants yields a statistically significant slope (elbow mean slope $=0.12, p<0.001$, shoulder mean slope $=0.19, p<0.05$ ): see last line in Table II under assisted.

\section{B. Unassisted Tracking Performance}

Tracking performance of the four tasks, unassisted by FES, that were completed at the beginning and end of each session was calculated, and an average taken for each task. Figs. 8 and 9 show tracking performance at the elbow and shoulder, respectively, over the course of the intervention. Statistically significant improved accuracy in tracking performance for all four tracking tasks was identified across all participants at the elbow and for two tasks at the shoulder. Table II shows the $p$-value and mean slope of these unassisted tasks. The positive mean slopes of all the unassisted tasks correspond to increases in performance of between $34.38 \%$ and $113.58 \%$ over the intervention period.

\section{Clinical Outcome Measures}

All clinical outcome measures improved after the intervention period (see Fig. 10). Improvements were seen at: impairment level, FMA increased by 6 (5.5) points from 44.8 (5.8) to 50.8 (8.2) out of a maximum score of 66 ; perceived ability, MAM-36 measure [39] increased by 3.6 (8.1) from 46.8 (10) to 50.4 (8); and actual ability in arm function, ARAT increased by 0.6 (3.7) points from 45.6 (10.5) to 50.8 (8.2) out of a maximum score of 57. The 9HPT time decreased from 145.3 (96) to 116.3 (88). Only the proximal arm section of the FMA, where the intervention was aimed and which measures at the impairment level of the ICF, identified statistically 
TABLE III

Results for the Clinical Outcome Assessments Showing Baseline and Post-Intervention Scores for the Five Participants

\begin{tabular}{|c|c|c|c|c|c|c|c|c|c|}
\hline $\mathrm{Pt} \mathrm{ID}^{1}$ & & MS1 & MS2 & MS3 & MS4 & MS5 & Mean (SD) & p-value & $\%$ change $^{2}$ \\
\hline MAM-36 $\%^{3}$ & Baseline & $\begin{array}{l}40 \\
57\end{array}$ & $\begin{array}{l}56 \\
57\end{array}$ & $\begin{array}{l}59 \\
54\end{array}$ & $\begin{array}{l}37 \\
39\end{array}$ & $\begin{array}{l}42 \\
45\end{array}$ & $\begin{array}{l}46.8(9.99) \\
50.4(8.05)\end{array}$ & 0.345 & 3.6 \\
\hline ARAT $(57)^{4}$ & $\begin{array}{l}\text { Baseline } \\
\text { Post }\end{array}$ & $\begin{array}{l}56 \\
53\end{array}$ & $\begin{array}{l}57 \\
57\end{array}$ & $\begin{array}{l}33 \\
33\end{array}$ & $\begin{array}{l}42 \\
41\end{array}$ & $\begin{array}{l}40 \\
47\end{array}$ & $\begin{array}{c}45.6(10.50) \\
46.2(9.55)\end{array}$ & 1.0 & 1.05 \\
\hline FMA $(66)^{4}$ & $\begin{array}{l}\text { Baseline } \\
\text { Post }\end{array}$ & $\begin{array}{l}54 \\
64\end{array}$ & $\begin{array}{l}46 \\
50\end{array}$ & $\begin{array}{l}44 \\
43\end{array}$ & $\begin{array}{l}41 \\
45\end{array}$ & $\begin{array}{l}39 \\
52\end{array}$ & $\begin{array}{l}44.8(5.81) \\
50.8(8.23)\end{array}$ & 0.078 & 9.09 \\
\hline FMA proximal arm $(36)^{4,5}$ & $\begin{array}{l}\text { Baseline } \\
\text { Post }\end{array}$ & $\begin{array}{l}30 \\
35\end{array}$ & $\begin{array}{l}23 \\
28\end{array}$ & $\begin{array}{l}20 \\
21\end{array}$ & $\begin{array}{l}18 \\
23\end{array}$ & $\begin{array}{l}21 \\
33\end{array}$ & $\begin{array}{l}22.4(4.62) \\
28.0(6.08)\end{array}$ & 0.039 & 15.56 \\
\hline FMA distal arm $(30)^{4,6}$ & $\begin{array}{l}\text { Baseline } \\
\text { Post }\end{array}$ & $\begin{array}{l}24 \\
29\end{array}$ & $\begin{array}{l}23 \\
22\end{array}$ & $\begin{array}{l}24 \\
22\end{array}$ & $\begin{array}{l}23 \\
22\end{array}$ & $\begin{array}{l}18 \\
19\end{array}$ & $\begin{array}{l}22.4(2.5) \\
22.8(3.7)\end{array}$ & 0.891 & 1.33 \\
\hline 9HPT $(300 \mathrm{secs})^{7}$ & $\begin{array}{l}\text { Baseline } \\
\text { Post }\end{array}$ & $\begin{array}{c}64 \\
229\end{array}$ & $\begin{array}{l}220 \\
143\end{array}$ & $\begin{array}{c}237 \\
43\end{array}$ & $\begin{array}{l}\text { utc }^{8} \\
\text { utc }^{8}\end{array}$ & $\begin{array}{l}70 \\
78\end{array}$ & $\begin{array}{l}145.3(96.39) \\
116.3(87.91)\end{array}$ & 0.465 & 8.17 \\
\hline
\end{tabular}

${ }^{1}$ participant identification. ${ }^{2}$ change in score divided by maximum possible score. ${ }^{3}$ motor ability measure with 36 items converted to percentage using Rasch analysis tables [39]. ${ }^{4}$ maximum score in brackets. ${ }^{5}$ proximal arm section of FMA encompassing Shoulder-Elbow-Forearm. ${ }^{6}$ distal arm section of FMA encompassing the wrist and hand. ${ }^{7}$ nine hold peg test measured in seconds. ${ }^{8}$ unable to complete.
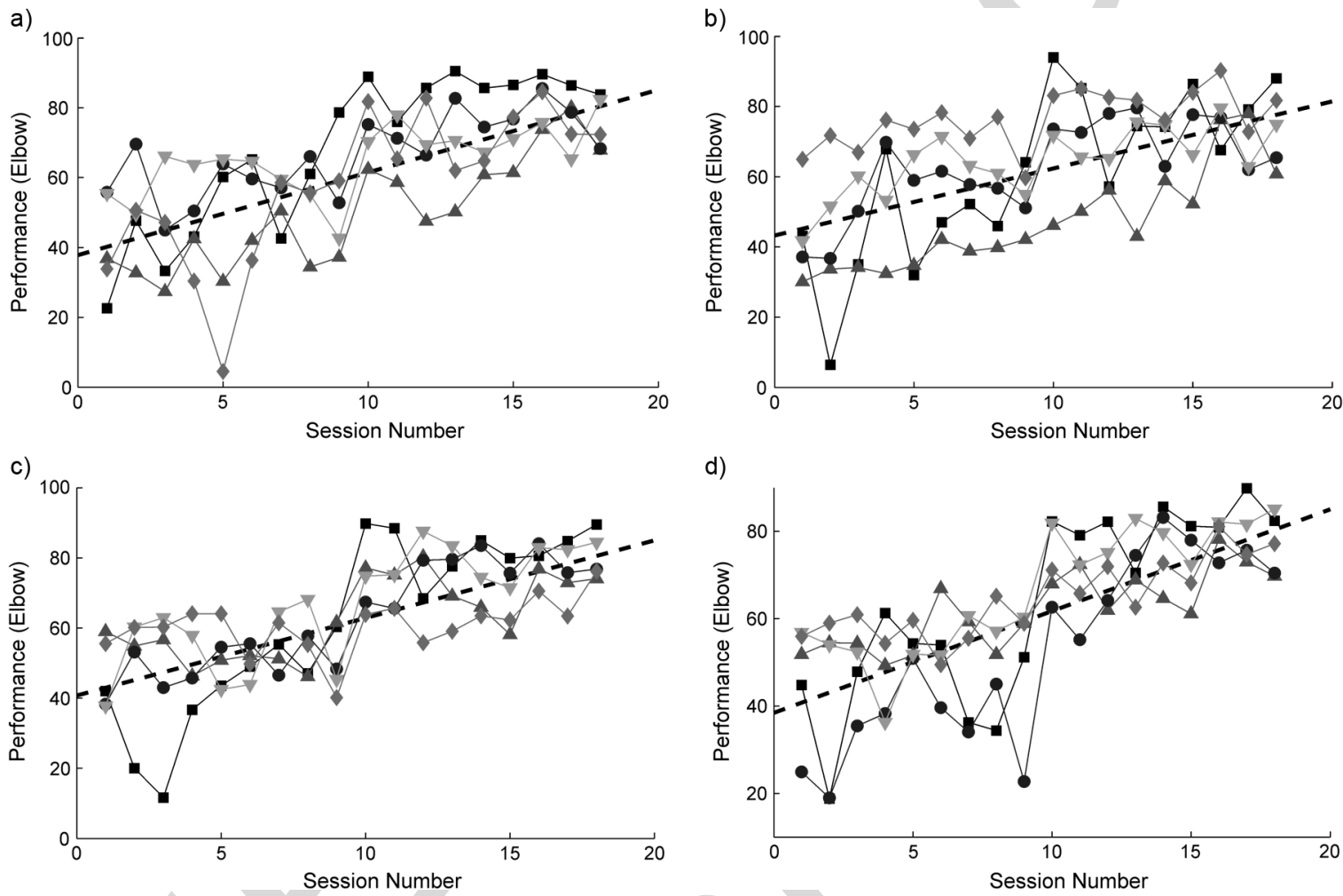

Fig. 8. Unassisted task tracking accuracy at the elbow. Each participant's performance is shown as a function of session for the four tracking tasks, unassisted by FES, before/after the intervention. The four tracking tasks are: a) center-proximal, b) center-distal, c) off-center-middle, and d) far-distal.

significant improvement $(z=-2.06, p=0.039)$ with an improvement of 5.6 (3.9) points from 22.4 (4.1) to 28 (5.4) out of a possible 36 points. This contrasts to the minimal 0.4 (2.7) point improvement out of a possible 30 points relating to the distal arm section of the FMA. Fig. 10(a) and (b) depict this. Only the area trained, the proximal arm, improved which suggests that specificity in training is required.

\section{Questionnaire}

All participants reported that now they were more aware of their affected arm, it did not feel weaker or tighter as a result of the intervention and that they were reaching out more easily. Two participants reported that they could now cut food using both a knife and fork whereas prior to the intervention, their carer would do this. All participants found two handed tasks easier such as folding clothes, cutting bread and personal hygiene (washing face). They all found the intervention enjoyable and it easy to understand what to do. All participants wanted additional muscles stimulated, wanted the intervention to continue, and would recommend the intervention to other pwMS. No participants found the FES particularly uncomfortable. Totals of Likert responses can be found in Appendix A.

\section{DISCUSSION}

The main aim of this study was to determine the feasibility and effectiveness of using the SAIL system for pwMS; this is the first time passive robotic arm support has been combined with FES to improve movement quality for this user group, and the 
a)

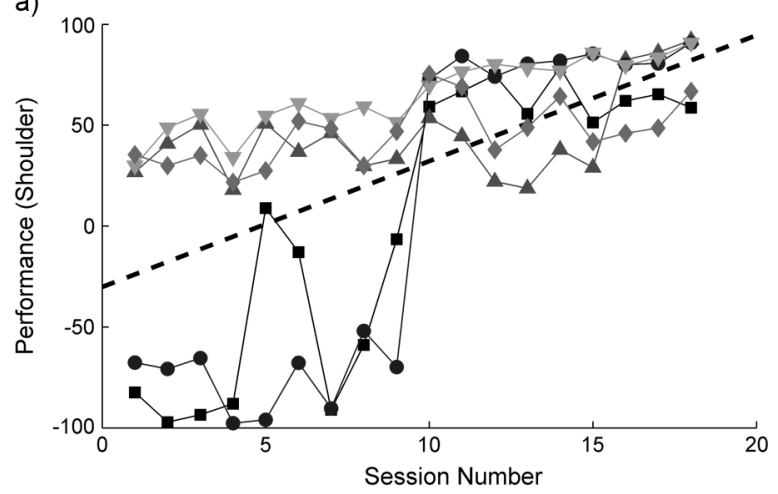

c)

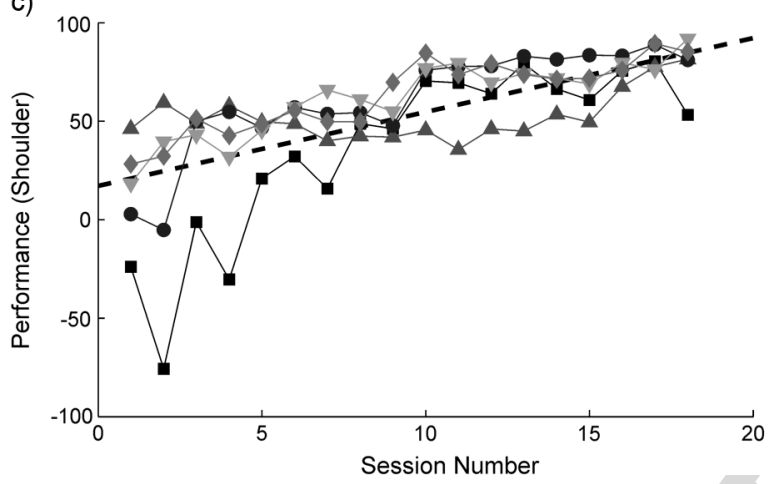

b)

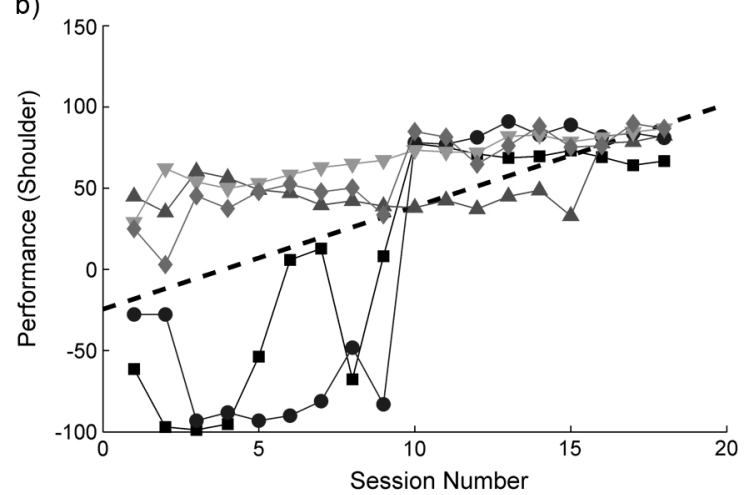

d)

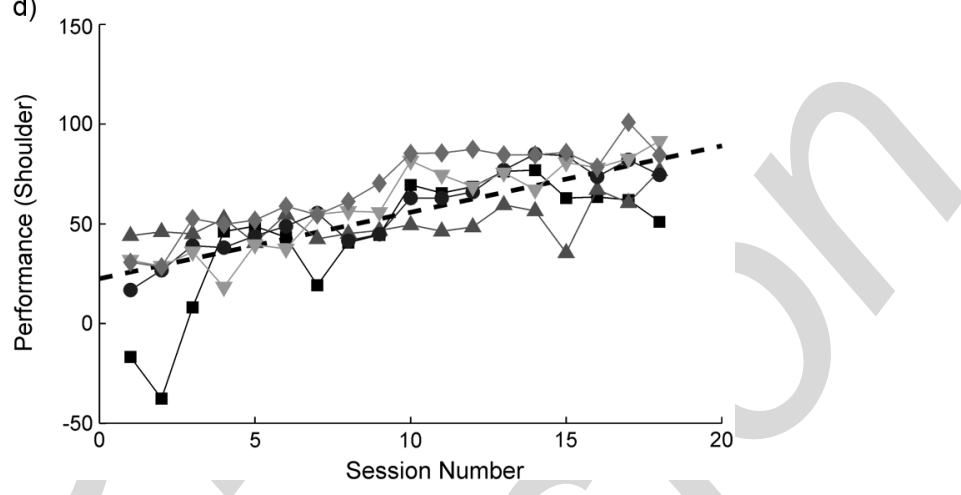

Fig. 9. Unassisted task tracking accuracy at the shoulder. Each participant's performance is shown as a function of session for the four tracking tasks, unassisted by FES, before/after the intervention. The four tracking tasks are: a) center-proximal, b) center-distal, c) off-center-middle, and d) far-distal.

first use of advanced model-based controllers to promote accuracy and voluntary effort. pwMS tolerated the intervention with no adverse effects and attended all 18 treatment sessions over a 10 week period. An improvement in arm awareness, better arm control and daily usage of their impaired arm was reported. Three important findings were identified following the intervention: improved tracking performance during the unassisted task; reduced FES required during the assisted tasks and an improvement in the proximal arm section of the FMA. Furthermore there were clear trends for clinical improvement in most measures by most patients.

The implication of improved tracking performance during assisted tasks over the treatment period, while less ILC mediated FES was required to achieve this, suggests that the participant's voluntary effort (muscle power and arm control) increased. Similarly, as participants progressed through the treatment sessions they were able to make more accurate reaching movements with no FES applied. All participants improved in the impairment domain of the ICF, measured by the proximal arm section of the FMA, where statistical significance was identified at the shoulder and elbow active movement control where the intervention was aimed. This is a new finding that indicates that movement quality improved following training. As with all statistical tests using small sample sizes, these conclusions must be treated with caution as they necessarily have limited power. The results however demonstrate the feasibility of the SAIL system with pwMS and suggest there is treatment potential for this novel system to aid recovery. These SAIL results are comparable to previous work undertaken on persons with stroke [24], [48]. Other robotic studies on pwMS [18], [20] have iden- tified improvements on arm capacity tests but this is the first study to show improvements in movement quality.

These findings are consistent with Lamers et al. [35] which identified that the FMA, or impairment outcome measurement, could predict changes in actual performed movements in daily life better. On group level, the 9HPT and ARAT showed no significant improvement but general trends were evident; two pwMS had large improvements in the 9HPT. Other studies of FES on the lower limb in pwMS [13], [14] also identified improvements at impairment rather than activity level. An explanation by Deutsch [5] is that improvements in impairment imply recovery has occurred rather than there being compensatory movement.

Fatigue is one of the most common symptoms in pwMS, but exercise has a positive effect on fatigue [49] and results from a pilot study combining exercise and FES [50] suggest reduced muscle fatigue. However, it should be noted that not all pwMS present with abnormal muscle fatigue [51]. Our results showed that all participants were able to increase the amount of exercise performed per session, indicating a possible improvement in muscle fatigue, but a future larger study should confirm this.

Progressive MS follows a predictable path with a direct relationship between duration of disease and increase in disability irrespective of whether this is PPMS or SPMS [52]. Two participants, MS1 and MS4, reported an exacerbation of their MS part way through the intervention period specifically relating to their impaired hand. MS4 had increased parasthesia (finger tips to elbow) and reduced finger movement (which was observed) directly following flu-like symptoms, and MS1 had altered temperature sensation. This increase in disability 
a) Fugl-Meyer (FMA) - Proximal Arm

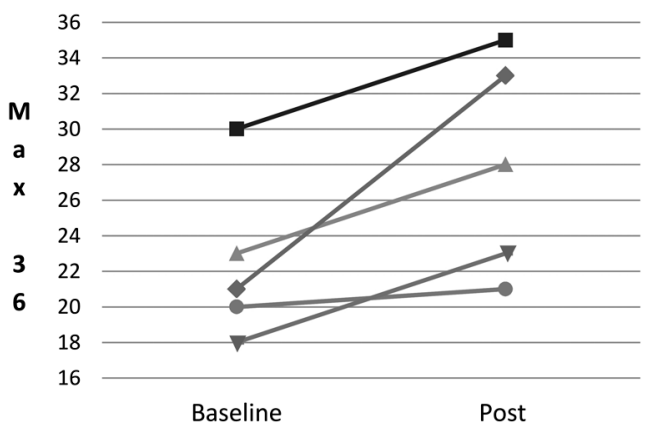

c) 9 Hole Peg Test (9HPT)

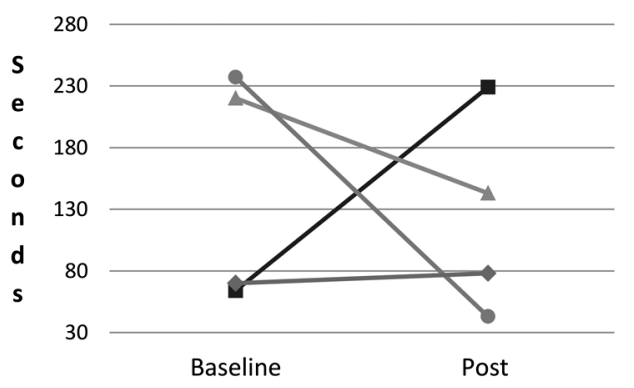

b) Fugl-Meyer (FMA) - Distal Arm

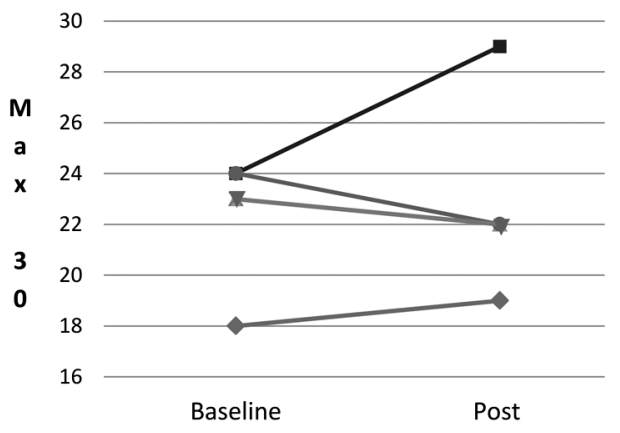

d) Manual Ability Measure (MAM-36)

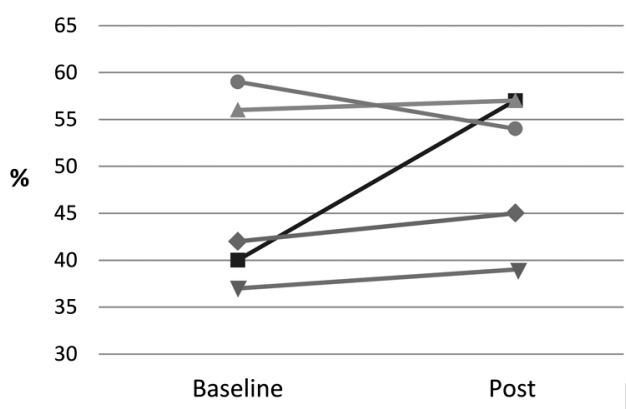

e) Action Research Arm Test (ARAT)

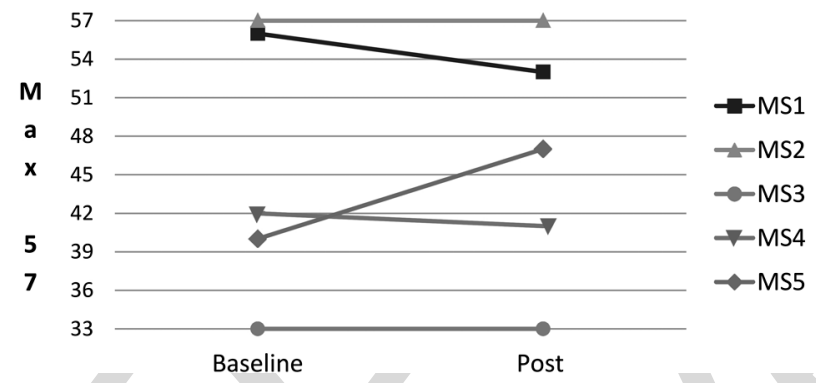

Fig. 10. The clinical outcome measures: a) the proximal arm section of the FMA (maximum value 36), b) the distal arm section of the FMA (maximum value 30), c) 9HPT, d) MAM-36, and e) ARAT showing the baseline and post assessment results for each participants.

is an expected consequence of progressive MS [52] and may explain anomalies in the clinical tests, 9HPT and ARAT. As current evidence supports physical exercise in pwMS, with active people having fewer relapses [53], it is unlikely that the intervention caused these changes. Both these participants had slightly reduced scores on the ARAT and took longer to complete the 9HPT after training: one unable to complete it due to finger flexor spasms and the other dropped her peg. Both the ARAT and 9HPT measure the upper limb in the activity domain of ICF but integrate fine pinch function/manual dexterity into the test, so any deterioration in participants' ability to pinch would adversely affect the score. SAIL did not stimulate hand/wrist muscles, working purely on the shoulder and elbow which may explain the minimal change in the ARAT, so it was encouraging to identify that these same two participants showed large improvements in the proximal arm section of the FMA and in the MAM-36. This suggests that their shoulder and elbow control and movement improved following the intervention even though their MS had worsened. The ARAT may not measure actual functions pwMS perform, explaining why their MAM-36 improved but not the ARAT. In view of this, the authors would recommend using another measure such as the Wolf Motor Function Test to assess improvements in proximal control.

\section{A. Participant Comments}

Comments from all participants regarding the best aspects of the intervention included: "... felt I regained control of the MS rather than MS controlling me..."; ". . . seeing what an impact it had on arm and the benefits of it..."; "...being able to move arm and realize that although I have progressive MS things can improve provided given the right intervention..."; "... improvement in physical abilities from it. .."; and ". . . arm is definitely stronger now and can do more things with it...". All participants indicated that now they were able to reach out more easily and two participants now could cut up their food independently with a knife and fork. The comments from this feasibility study serve to elucidate that even in a progressive disease such as MS, improvements in upper limb function resulting from this intervention were noticed by all participants. More importantly the upper limb improvements had translated into their daily life and were meaningful to them: improvements 
that the ARAT could not detect. Useful feedback from participants about using the SAIL system can be used in future enhancements.

\section{B. Limitations of the Study}

Limitations included a small sample size, unblinded clinical evaluators, no control group and lack of a follow up (due to time constraints), signifying that the findings should be interpreted with caution. We cannot generalize the findings from this small group given that it is well-known that pwMS can present with a wide variety of symptoms including fatigue, weakness, spasticity, and sensory loss. However, we note that the system was well tolerated by all members of the participant group which encompassed various levels of disability.

This was a proof of concept study that motivates and lays the groundwork for a future study in terms of feasibility, participation rates, resource requirements and sample estimation data. The sufficiently powered future study is expected to have three arms: a control group receiving no intervention; the SAIL system; and mechanical support alone. This would identify what learning results from practicing a task and clarify the extent to which the SAIL system assists with reducing impairment, thus highlighting whether SAIL provides an effective treatment for MS upper limb impairment. The future study's sample should focus specifically on arm dysfunction and exclude participants with cerebellar disorders. As the clinical outcome measures incorporate the entire arm with the hand/wrist as an essential component, a future study should include stimulation of the wrist extensors/flexors so that therapy is delivered to the entire arm including the wrist/hand. It may also be beneficial to practice functional tasks involving manipulation of objects, in addition to the reaching tasks. By adding more functional tasks such as pressing a light switch, it is possible that improvements might better translate into everyday tasks.

\section{CONCLUSION}

This study demonstrated the feasibility of using advanced control approaches combined with FES and robotic support to improve arm movement for pwMS. There was excellent adherence by pwMS to the intervention and no side effects were reported. The intervention resulted in improvements in reaching accuracy with and without FES and reduced impairment in the proximal arm. As these technologies are developed, they will allow an increased intensity of rehabilitation to be delivered with minimal therapist input. The improvements identified by the outcome measures combined with the positive feedback from all participants concerning their improved arm movement and control should not be ignored. This study included a novel combination of interventions that warrants further investigation.

\section{APPENDIX A}

SEMI-STRUCTURED INTERVIEW QUESTIONS AND LIKERT RESPONSE [47]

See Table IV.
Table IV

Semi-STRUCtured INTERVIEW QueStions AND LiKert Response [47]

\begin{tabular}{|c|c|c|c|c|c|c|}
\hline \multirow[t]{2}{*}{ Category/Statement/Question } & \multirow{2}{*}{$\begin{array}{l}\text { Quest- } \\
\text { ion } \\
\text { Style }\end{array}$} & \multicolumn{5}{|c|}{ Likert Responses } \\
\hline & & 瑥。 & 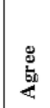 & 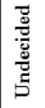 & 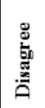 & 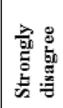 \\
\hline \multicolumn{7}{|l|}{ A. System Effectiveness } \\
\hline 1. I am now more aware of my affected arm & Likert & 5 & & & & \\
\hline 2. My arm feels weaker & Likert & & & & 2 & 3 \\
\hline 3. My arm feels tighter & Likert & & & 1 & 3 & 1 \\
\hline 4. I can reach out with my arm more easily & Likert & 3 & 2 & & & \\
\hline 5. I can now pick up objects & Likert & 1 & 3 & 1 & & \\
\hline $\begin{array}{l}\text { 6. Are you now able to do things that you } \\
\text { could not do before? (Yes/No. Please give } \\
\text { examples and provide as much information } \\
\text { as possible) }\end{array}$ & Open & \multicolumn{5}{|l|}{ All yes } \\
\hline $\begin{array}{l}\text { 7. Are you now able to do things better than } \\
\text { you could before? (Yes/No. Please give } \\
\text { examples and provide as much information } \\
\text { as possible) }\end{array}$ & Open & \multicolumn{5}{|l|}{ All yes } \\
\hline $\begin{array}{l}\text { 8. Can you now perform any two handed tasks } \\
\text { more easily? (Yes/No; Please give } \\
\text { examples and provide as much information } \\
\text { as possible) }\end{array}$ & Open & \multicolumn{5}{|l|}{ All yes } \\
\hline $\begin{array}{l}\text { CARER/SPOUSE/RELATIVE } \\
\text { Do you think that (participant name) is now able } \\
\text { to: } \\
\text { i. do things that he/she could not do } \\
\text { ii. dofore? } \\
\text { before? } \\
\text { (Yes/No. Please give examples and provide as } \\
\text { much information as possible) }\end{array}$ & Open & \multicolumn{5}{|c|}{ Not asked } \\
\hline \multicolumn{7}{|l|}{ B. System Usability } \\
\hline 9. I did not find the treatment enjoyable & Likert & & & & 1 & 4 \\
\hline 10. It was easy to understand what I had to do & Likert & 4 & 1 & & & \\
\hline $\begin{array}{l}\text { 11. It was difficult to put my arm in the arm } \\
\text { holder. } \\
\text { MS3 - couldn't do it on own, wasn't } \\
\text { difficult with Trish's help. }\end{array}$ & Likert & & 1 & & 3 & 1 \\
\hline 12. The arm holder was comfortable & Likert & 3 & 2 & & & \\
\hline 13. The stimulation was uncomfortable & Likert & & & 1 & 3 & 1 \\
\hline $\begin{array}{l}\text { 14. The target (i.e., the moving ball) was easy } \\
\text { to see } \\
\text { MS1 - due to visual problems - sometimes } \\
\text { difficulty to see - usually fine }\end{array}$ & Likert & 4 & & & 1 & \\
\hline $\begin{array}{l}\text { 15. The trajectory (i.e., length, height, } \\
\text { direction) was easy to see }\end{array}$ & Likert & 3 & 2 & & & \\
\hline $\begin{array}{l}\text { 16. I did not understand the graphs showing my } \\
\text { performance }\end{array}$ & Likert & & 1 & & 3 & 1 \\
\hline \multicolumn{7}{|l|}{$\begin{array}{l}\text { C. Questions about how the system could be } \\
\text { improved }\end{array}$} \\
\hline $\begin{array}{l}\text { 17. Adding games would add to my motivation } \\
\text { and enjoyment of the treatment }\end{array}$ & Likert & 2 & 1 & 1 & 1 & \\
\hline $\begin{array}{l}\text { 18. I would not like to have more arm muscles } \\
\text { stimulated }\end{array}$ & Likert & & & & 2 & 3 \\
\hline $\begin{array}{l}\text { 19. How do you think the task could be } \\
\text { improved? }\end{array}$ & Open & & & & & \\
\hline \multicolumn{7}{|l|}{ D. General Questions } \\
\hline $\begin{array}{l}\text { 20. I would not recommend the treatment to } \\
\text { other people who have had MS }\end{array}$ & Likert & & & & 1 & 4 \\
\hline $\begin{array}{l}\text { 21. I would have liked to have continued longer } \\
\text { with the treatment }\end{array}$ & Likert & 2 & 3 & & & \\
\hline $\begin{array}{l}\text { 22. Looking back on it, was taking part in this } \\
\text { study worthwhile for you? (Yes/No; please } \\
\text { provide as much information as possible) }\end{array}$ & Open & \multicolumn{5}{|l|}{ All yes } \\
\hline 23. What were the worst aspects of it? & Open & & & & & \\
\hline 24 . What were the best aspects of it? & Open & & & & & \\
\hline \multicolumn{7}{|l|}{ E. Dreamtime } \\
\hline $\begin{array}{l}\text { 25. If we could design the ideal rehabilitation } \\
\text { system describe five features it should } \\
\text { have: }\end{array}$ & Open & & & & & \\
\hline $\begin{array}{l}\text { 26. If we could stimulate more muscles which } \\
\text { movements would you like? }\end{array}$ & Open & & & & & \\
\hline
\end{tabular}




\section{ACKNOWLEDGMENT}

The authors would like to thank the people with MS who participated in this study. They would also like to thank S. K. Wee and E. Hallewell for conducting the clinical assessments.

\section{REFERENCES}

[1] F. Khan, L. Turner-Stokes, L. Ng, and T. Kilpatrick, "Multidisciplinary rehabilitation for adults with multiple sclerosis," Cochrane Database Syst. Rev., Tech. Rep. CD006036, 2007.

[2] A. I. Spooren, A. A. Timmermans, and H. A. Seelen, "Motor training programs of arm and hand in patients with MS according to different levels of the ICF: A systematic review," BMC Neurol, vol. 12, p. 49, 2012.

[3] S. Johansson, C. Ytterberg, I. Claesson, J. Lindberg, J. Hillert, M. Andersson, L. Widen Holmqvist, and L. Koch, "High concurrent presence of disability in multiple sclerosis," J. Neurol., vol. 254, pp. 767-773, 2007.

[4] U. Einarsson, K. Gottberg, S. Fredikson, L. Von Koch, and L. W. Holmqvist, "Activities of daily living and social activities in people with multiple sclerosis in Stockholm county," Clin. Rehabil., vol. 20, pp. 543-551, 2006.

[5] J. E. Deutsch, A. S. Merians, S. Adamovich, H. Poizner, and G. C. Burdea, "Development and application of virtual reality technology to improve hand use and gait of individuals post-stroke," Restor. Neurol. Neurosci., vol. 22, pp. 371-386, 2004.

[6] T. Paillard, F. Noe, P. Passelergue, and P. Dupui, "Electrical stimulation superimposed onto voluntary muscular contraction," Sports Med. vol. 35, pp. 951-966, 2005.

[7] M. Glanz, S. Klawansky, W. Stason, C. Berkley, and T. C. Chalmers, "Functional electrostimulation in poststroke rehabilitation: A meta-analysis of the randomized controlled trials," Arch. Phys. Med. Rehabil., vol. 77, pp. 549-553, 1996.

[8] J. Glinsky, L. Harvey, and P. Van Es, "Efficacy of electrical stimulation to increase muscle strength in people with neurological conditions: A systematic review," Physiother Res. Int., vol. 12, pp. 175-194, 2007.

[9] R. Martin, C. Sadowsky, K. Obst, B. Meyer, and J. Mcdonald, "Functional electrical stimulation in spinal cord injury: From theory to practice," Top Spinal Cord Inj. Rehabil., vol. 18, pp. 28-33, 2012.

[10] Y. J. Chang, M. J. Hsu, S. M. Chen, C. H. Lin, and A. M. Wong, "Decreased central fatigue in multiple sclerosis patients after 8 weeks of surface functional electrical stimulation," J. Rehabil. Res. Dev., vol. 48, pp. 555-564, 2011.

[11] J. E. Esnouf, P. N. Taylor, G. E. Mann, and C. L. Barrett, "Impact on activities of daily living using a functional electrical stimulation device to improve dropped foot in people with multiple sclerosis, measured by the canadian occupational performance measure," Mult. Scler., vol. 16, pp. 1141-1147, 2010

[12] L. Paul, D. Rafferty, S. Young, L. Miller, P. Mattison, and A. Mcfadyen, "The effect of functional electrical stimulation on the physiological cost of gait in people with multiple sclerosis," Mult. Scler., vol. 14, pp. 954-961, 2008.

[13] L. Hughes, A. Donnelly, G. Rainsford, and S. Coote, "Augmenting an exercise programme with electrical stimulation for people with multiple sclerosis-The effect on strength and fatigue," Physiotherapy, vol. 97, pp. S511-S512, 2011.

[14] T. Broekmans, M. Roelants, P. Feys, G. Alders, D. Gijbels, I. Hanssen, P. Stinissen, and B. O. Eijnde, "Effects of long-term resistance training and simultaneous electro-stimulation on muscle strength and functional mobility in multiple sclerosis," Mult. Scler., vol. 17, pp. 468-477, 2011.

[15] J. N. Ratchford, W. Shore, E. R. Hammond, J. G. Rose, R. Rifkin, P. Nie, K. Tan, M. E. Quigg, B. J. De Lateur, and D. A. Kerr, "A pilot study of functional electrical stimulation cycling in progressive multiple sclerosis," NeuroRehabil., vol. 27, pp. 121-128, 2010.

[16] G. Kwakkel, B. J. Kollen, and H. I. Krebs, "Effects of robot-assisted therapy on upper limb recovery after stroke: A systematic review," Neurorehab. Neural Repair, vol. 22, pp. 111-121, 2008.

[17] J. Mehrholz, A. Hadrich, T. Platz, J. Kugler, and M. Pohl, "Electromechanical and robot-assisted arm training for improving generic activities of daily living, arm function, and arm muscle strength after stroke," Cochrane Database Syst. Rev., vol. 6, p. CD006876, 2012.

[18] D. Gijbels, I. Lamers, L. Kerkhofs, G. Alders, E. Knippenberg, and P. Feys, "The armeo spring as training tool to improve upper limb functionality in multiple sclerosis: A pilot study," J. Neuroeng. Rehabil., vol. 8, pp. 5-5, 2011.
[19] E. Vergaro, V. Squeri, G. Brichetto, M. Casadio, P. Morasso, C. Solaro, and V. Sanguineti, "Adaptive robot training for the treatment of incoordination in multiple sclerosis," J. Neuroeng. Rehabil., vol. 7, pp. 37-37, 2010.

[20] I. Carpinella, D. Cattaneo, S. Abuarqub, and M. Ferrarin, "Robot-based rehabilitation of the upper limbs in multiple sclerosis: Feasibility and preliminary results," J. Rehabil. Med. (Stiftelsen Rehabiliteringsinformation), vol. 41, pp. 966-970, 2009.

[21] M. Casadio, V. Sanguineti, P. Morasso, and C. Solaro, "Abnormal sensorimotor control, but intact force field adaptation, in multiple sclerosis subjects with no clinical disability," Mult. Scler., vol. 14, pp. 330-342, 2008.

[22] V. Squeri, E. Vergaro, G. Brichetto, M. Casadio, P. G. Morasso, C. Solaro, and V. Sanguinetti, "Adaptive robot training in the rehabilitation of incoordination in multiple sclerosis: A pilot study," in Proc. IEEE 10th Int. Conf. Rehabil. Robot., 2007, pp. 364-370.

[23] I. Carpinella, D. Cattaneo, R. Bertoni, and M. Ferrarin, "Robot training of upper limb in multiple sclerosis: Comparing protocols with or without manipulative task components," IEEE Trans Neural Syst. Rehabil. Eng., vol. 20, no. 3, pp. 351-360, 2012.

[24] A. M. Hughes, C. T. Freeman, J. H. Burridge, P. H. Chappell, P. L. Lewin, and E. Rogers, "Feasibility of iterative learning control mediated by functional electrical stimulation for reaching after stroke," $J$. Neurorehabil. Neural Repair, vol. 23, pp. 559-568, 2009.

[25] K. L. Meadmore, A. M. Hughes, C. T. Freeman, J. H. Burridge, D. Tong, Z. Cai, and E. Rogers, " $<$ PLEASE PROVIDE PAGE NUMBERS.> Functional electrical stimulation mediated by iterative learning control and $3 \mathrm{D}$ robotics reduces motor impairment in chronic stroke," J. Neuroeng. Rehabil., vol. 32, no. 9, 2012.

[26] C. T. Freeman, "Upper limb electrical stimulation using input-output linearization and iterative learning control," IEEE Trans. Control Syst. Technol. [Online]. Available: http://dx.doi.org/10.1109/TCST.2014. 2363412

[27] C. T. Freeman and Y. Tan, "Iterative learning control with mixed constraints for point-to-point tracking," IEEE Trans. Control Syst. Technol., vol. 21, no. 3, pp. 604-616, May 2013.

[28] C. T. Freeman, T. Exell, K. L. Meadmore, E. Hallewell, and A.-M. Hughes, "Computational models of upper limb motion during functional reaching tasks for application in FES based stroke rehabilitation," Biomed. Eng. J., 10.1515/bmt-2014-0011.

[29] D. H. Owens, C. T. Freeman, and B. Chu, "Multivariable norm optimal iterative learning control with auxiliary optimization," Int. J. Contol, vol. 86, no. 6, pp. 1026-1045, 2013.

[30] F. Le, I. Markovsky, C. T. Freeman, and E. Rogers, "Identification of electrically stimulated muscle models of stroke patients," Control Eng. Practice, vol. 18, pp. 396-407, 2010.

[31] C. T. Freeman, A. M. Hughes, J. H. Burridge, P. H. Chappell, P. L. Lewin, and E. Rogers, "A model of the upper extremity using surface FES for stroke rehabilitation," ASME J. Biomech. Eng., vol. 131, no. 3, p. 031011, 2009.

[32] I. Lamers, A. A. Timmermans, L. Kerkhofs, D. Severijns, B. Van Wijmeersch, and P. Feys, "Self-reported use of the upper limbs related to clinical tests in persons with multiple sclerosis," Disabil. Rehabil., vol. 35, pp. 2016-2020, 2013.

[33] N. Yozbatiran, L. Der-Yeghiaian, and S. C. Cramer, "A standardized approach to performing the action research arm test," Neurorehabil. Neural Repair, vol. 22, pp. 78-90, 2008.

[34] R. C. Lyle, "A performance test for assessment of upper limb function in physical rehabilitation treatment and research," Int. J. Rehabil. Res., vol. 4, pp. 483-492, 1981.

[35] I. Lamers, L. Kerkhofs, J. Raats, D. Kos, B. Van Wijmeersch, and P. Feys, "Perceived and actual arm performance in multiple sclerosis: Relationship with clinical tests according to hand dominance," Mult. Scler., vol. 19, pp. 1341-1348, 2013.

[36] V. Mathiowetz, K. Weber, N. Kashman, and G. Volland, "Adult norms for the nine hole peg test of finger dexterity," Occupational Therapy $J$. Res., vol. 5, pp. 24-38, 1985.

[37] D. E. Goodkin, D. Hertsgaard, and J. Seminary, " $<$ PLEASE PROVIDE YEAR.> Upper extremity function in multiple sclerosis: Improving assessment sensitivity with box-and-block and nine-hole peg tests," Arch. Phys. Med. Rehabil., vol. 69, pp. 850-854.

[38] B. Kopp, A. Kunkel, H. Flor, T. Platz, U. Rose, K. H. Mauritz, K. Gresser, K. L. Mcculloch, and E. Taub, "The arm motor ability test: Reliability, validity, and sensitivity to change of an instrument for assessing disabilities in activities of daily living," Arch. Phys. Med. Rehabil., vol. 78, pp. 615-620, 1997. 
[39] C. C. Chen and R. K. Bode, "Psychometric validation of the manual ability measure-36 (MAM-36) in patients with neurologic and musculoskeletal disorders," Arch. Phys. Med. Rehabil., vol. 91, pp. 414-420, 2010.

[40] A. R. Fugl-Meyer, L. Jaasko, I. Leyman, S. Olsson, and S. Steglind, "The post-stroke hemiplegic patient. 1. A method for evaluation of physical performance," Scand. J. Rehabil. Med., vol. 7, pp. 13-31, 1975.

[41] P. W. Duncan, M. Propst, and S. G. Nelson, "Reliability of the FuglMeyer assessment of sensorimotor recovery following cerebrovascular accident," Phys. Ther., vol. 63, pp. 1606-1610, 1983.

[42] D. J. Gladstone, C. J. Danells, and S. E. Black, "The Fugl-Meyer assessment of motor recovery after stroke: A critical review of its measurement properties," Neurorehabil. Neural Repair, vol. 16, pp. 232-240, 2002.

[43] T. Platz, C. Pinkowski, F. van Wijck, I. H. Kim, P. di Bella, and G. Johnson, "Reliability and validity of arm function assessment with standardized guidelines for the Fugl-Meyer test, action research arm test and box and block test: A multicentre study," Clin. Rehabil., vol. 19, no. 4, pp. 404-411, Jun. 2005.

[44] H. Bastiaens, G. Alders, P. Feys, S. Notelaers, K. Coninx, L. Kerkhofs, V. Truyens, R. Geers, and A. Goedhart, " $<$ PLEASE PROVIDE PAGE NUMBERS OR LOCATION.> Facilitating robot-assisted training in MS patients with arm paresis: A procedure to individually determine gravity compensation," in Proc. 12th IEEE Int. Conf. Rehabil. Robot., 2011.

[45] C. H. Polman and R. A. Rudick, "The multiple sclerosis functional composite: A clinically meaningful measure of disability," Neurol., vol. 74, pp. S8-S15, 2010.

[46] S. Whitling, N. B. Lincoln, G. Bhavnani, and J. Cockburn, "Rivermead perceptual assessment battery," Occupational Therapy in Health Care, vol. 3, pp. 209-210, 1986.

[47] R. Turk, J. Burridge, D. Merrill, A.-M. Hughes, G. Cosendai, and J. Schulman, " $<$ PLEASE PROVIDE PAGE NUMBERS OR LOCATION.> Clinical effectiveness and participant perceptions of an implanted closed-loop neurostimulator-sensor system for arm rehabilitation post-stroke," in Proc. Int. Functional Elect. Stimulation Soc. Annu. Conf., 2008.

[48] K. L. Meadmore, A.-M. Hughes, C. T. Freeman, Z. Cai, D. Tong, J. H. Burridge, and E. Rogers, "<PLEASE PROVIDE PAGE NUMBERS.> Functional electrical stimulation mediated by iterative learning control and 3D robotics reduces motor impairment in chronic stroke," J. Neuroeng. Rehabil., vol. 9, no. 32, 2012.

[49] L. A. Pilutti, T. A. Greenlee, R. W. Motl, M. S. Nickrent, and S. J. Petruzzello, "Effects of exercise training on fatigue in multiple sclerosis: A meta-analysis," Psychosom. Med., vol. 75, no. 6, pp. 575-580, Jul.-Aug. 2013.
[50] S. Coote, L. Hughes, G. Rainsford, C. Minogue, and A. Donnelly, " $>$ PLEASE PROVIDE URL OR VOLUME AND PAGE NUMBERS.> A pilot randomized trial of progressive resistance exercise augmented by neuromuscular electrical stimulation for people with multiple sclerosis who use walking aids," Arch. Phys. Med. Rehabil., 2014.

[51] D. Severijns, I. Lamers, L. Kerkhofs, and P. Feys, “<PLEASE PROVIDE DOI NUMBER.> Hand grip fatigability in persons with multiple sclerosis according to hand dominance and disease progression," J. Rehabil. Med., Sep. 2014.

[52] C. Confavreux and S. Vukusic, "Natural history of multiple sclerosis: A unifying concept," Brain, vol. 129, pp. 606-616, 2006.

[53] A. Tallner, A. Waschbisch, I. Wenny, S. Schwab, C. Hentschke, K. Pfeifer, and M. Maurer, "Multiple sclerosis relapses are not associated with exercise," Mult. Scler., vol. 18, pp. 232-235, 2012.

\section{Patrica Sampson PLEASE PROVIDE BIOGRAPHICAL INFORMA- TION AND PHOTO IF AVAILABLE FOR ALL AUTHORS.}

Chris Freeman Please provide biographical information.

Susan Coote Please provide biographical information.

Sara Demain Please provide biographical information.

Peter Feys Please provide biographical information.

Katie Meadmore Please provide biographical information.

Ann-Marie Hughes Please provide biographical information. 